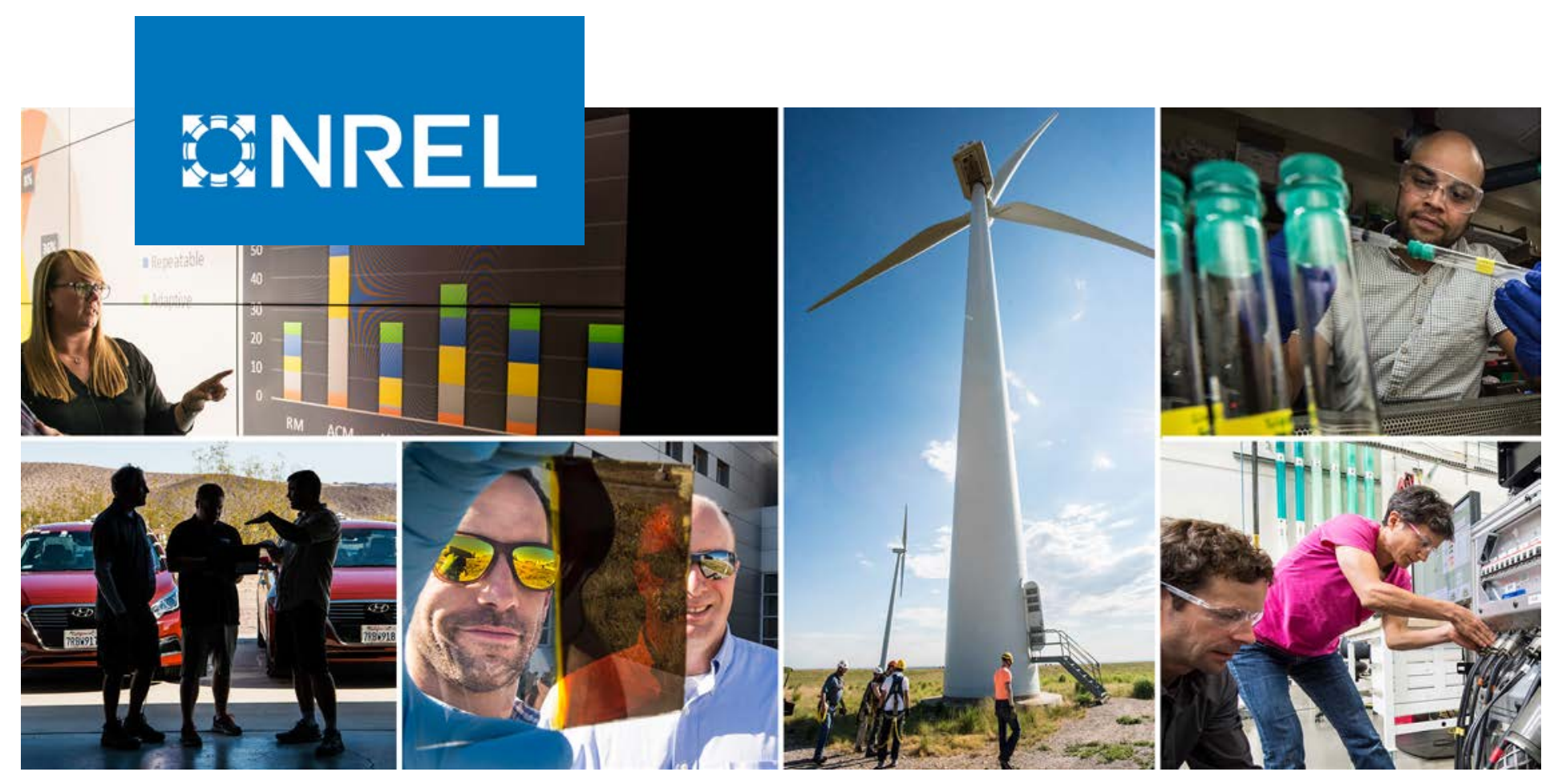

\title{
India 2030 Wind and Solar Integration Study: Interim Report
}

David Palchak, Ilya Chernyakhovskiy, Thomas Bowen, and Vinayak Narwade

National Renewable Energy Laboratory

NREL is a national laboratory of the U.S. Department of Energy

Office of Energy Efficiency \& Renewable Energy

Operated by the Alliance for Sustainable Energy, LLC

This report is available at no cost from the National Renewable Energy Laboratory (NREL) at www.nrel.gov/publications.
Technical Report

NREL/TP-6A20-73854

May 2019 


\title{
GNREL
}

\section{India 2030 Wind and Solar Integration Study: Interim Report}

\author{
David Palchak, Ilya Chernyakhovskiy, Thomas Bowen, \\ and Vinayak Narwade
}

National Renewable Energy Laboratory

Suggested Citation

Palchak, David, Ilya Chernyakhovskiy, Thomas Bowen, and Vinayak Narwade. 2019. India 2030 Wind and Solar Integration Study: Interim Report. Golden, CO: National Renewable Energy Laboratory. NREL/TP-6A20-73854. https://www.nrel.gov/docs/fy19osti/73854.pdf.

NREL is a national laboratory of the U.S. Department of Energy Office of Energy Efficiency \& Renewable Energy Operated by the Alliance for Sustainable Energy, LLC

This report is available at no cost from the National Renewable Energy Laboratory (NREL) at www.nrel.gov/publications.

Contract No. DE-AC36-08GO28308
Technical Report NREL/TP-6A20-73854 May 2019

National Renewable Energy Laboratory 15013 Denver West Parkway Golden, CO 80401 303-275-3000 • www.nrel.gov 


\section{NOTICE}

This work was authored by the National Renewable Energy Laboratory, operated by Alliance for Sustainable Energy, LLC, for the U.S. Department of Energy (DOE) under Contract No. DE-AC36-08GO28308. Funding provided by the Children's Investment Fund Foundation and the William and Flora Hewlett Foundation. The views expressed herein do not necessarily represent the views of the DOE or the U.S. Government.

This report is available at no cost from the National Renewable Energy Laboratory (NREL) at www.nrel.gov/publications.

U.S. Department of Energy (DOE) reports produced after 1991 and a growing number of pre-1991 documents are available free via www.OSTI.gov.

Cover Photos by Dennis Schroeder: (clockwise, left to right) NREL 51934, NREL 45897, NREL 42160, NREL 45891, NREL 48097, NREL 46526.

NREL prints on paper that contains recycled content. 


\section{Abstract}

India has established several targets for renewable energy capacity growth in the coming years, most notably the target of deploying 175 gigawatts $(\mathrm{GW})$ of generation capacity from wind, solar, biomass, and small hydropower by 2022, and furthering that vision with India's Nationally Determined Contribution target of $40 \%$ renewable electricity capacity (including hydro) by 2030 (GOI 2015). Given the rapid and significant changes to India's power system to help meet these targets, the objective of this interim report is to understand the operational challenges for India's power grid in 2030. The primary contribution of this report is to establish a 2030 unit commitment and dispatch model of India's grid, with hourly temporal resolution, high spatial resolution of renewable energy resources, interstate transmission constraints, and unit-level generator characteristics. Annual simulations of 2030 operations demonstrate that a $22 \%$ annual penetration of wind and solar is manageable by India's grid. Most days in the year do not show signs of stress, and $99.97 \%$ of energy is served with the plans as presented. Average coal plant load factors are $70 \%$ for the year, up from relatively low plant load factors in recent years (Patel 2018). However, the results highlight specific challenges the grid may face during a small number of high-demand periods, resulting in unserved energy. The drivers behind the unserved energy suggest that this could be avoided with better coordination in scheduling.

This report is part of a broader set of analyses under the Energy Transitions Commission (ETC), which includes collaborations with The Energy and Resources Institute (TERI), Climate Policy Initiative (CPI), and a broad stakeholder community. 


\section{Acknowledgments}

The authors are grateful to those who provided comments and support throughout the study, including Thomas Spencer, Neshwin Rodrigues, and Raghav Pachouri (The Energy and Resources Institute [TERI]); Udetanshu, Brendan Pierpont, and David Nelson (Climate Policy Initiative [CPI]); Priya Sreedharan (United States Agency for International Development [USAID]); and Jaquelin Cochran and Amy Rose (National Renewable Energy Laboratory [NREL]). Substantial input on study framework and assumptions were deliberated with the Energy Transitions Commission (ETC) research group made up of TERI, CPI, and NREL, for which we are thankful. A special thank you to Thomas Spencer for his leadership of this group. We are also grateful to the broader stakeholder community of the ETC, which has provided invaluable feedback.

The Energy and Resources Institute team of Neshwin Rodrigues, Aastha Sharma, and Alekhya Datta provided critical data for the renewable energy generation profiles based on their analysis of likely candidates for wind and solar generation. Raghav Pachouri and Thomas Spencer provided the national load profile data from which state load profiles were derived.

This work is funded by the Children's Investment Fund Foundation (CIFF) and the William and Flora Hewlett Foundation. 


\section{List of Acronyms}

$\begin{array}{ll}\text { ATC } & \text { available transfer capacity } \\ \text { CEA } & \text { Central Electricity Authority } \\ \text { CERC } & \text { Central Electricity Regulatory Commission } \\ \text { CPI } & \text { Climate Policy Initiative } \\ \text { CPS } & \text { Current Policy Scenario } \\ \text { ETC } & \text { Energy Transitions Commission } \\ \text { GTG } & \text { Greening the Grid } \\ \text { GW } & \text { gigawatts } \\ \text { GWh } & \text { gigawatt-hours } \\ \text { kV } & \text { kilovolt } \\ \text { NEP } & \text { National Electricity Plan } \\ \text { NREL } & \text { National Renewable Energy Laboratory } \\ \text { PASA } & \text { Projected Assessment of the System Adequacy } \\ \text { PLF } & \text { plant load factor } \\ \text { POSOCO } & \text { Power Systems Operation Corporation Limited } \\ \text { PRM } & \text { planning reserve margins } \\ \text { RLDC } & \text { Regional Load Dispatch Center } \\ \text { SLDC } & \text { State Load Dispatch Center } \\ \text { SRMC } & \text { short-run marginal cost } \\ \text { TERI } & \text { The Energy and Resources Institute } \\ \text { TWh } & \text { terawatt hours } \\ \text { USAID } & \text { U.S. Agency for International Development } \\ \text { UT } & \text { Union Territories } \\ \text { NREL } & \text { National Renewable Energy Laboratory } \\ & \end{array}$




\section{Table of Contents}

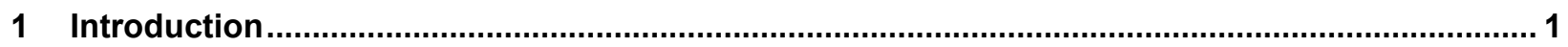

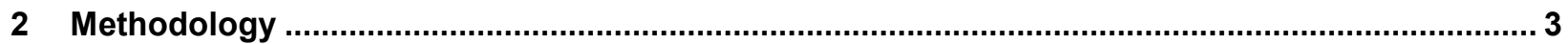

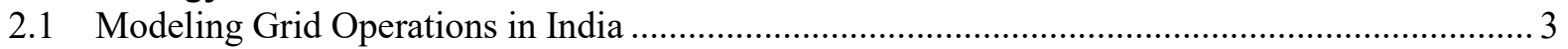

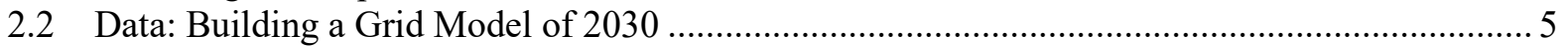

2.2.1 Greening the Grid - India Production Cost Model of 2022 ......................................... 5

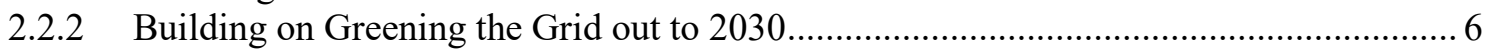

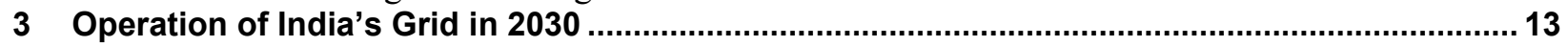

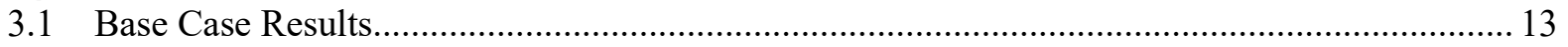

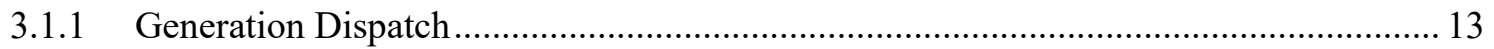

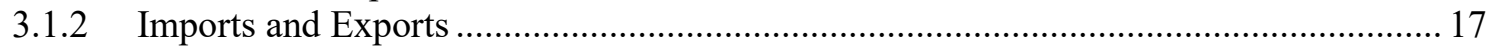

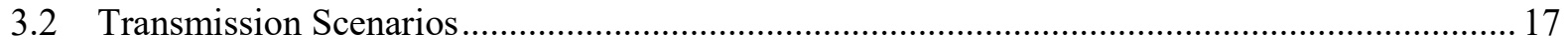

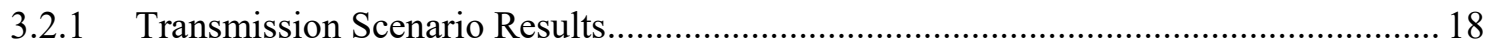

3.3 Supply and Demand Balance ........................................................................................... 22

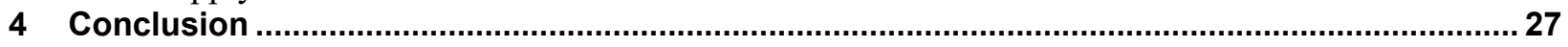

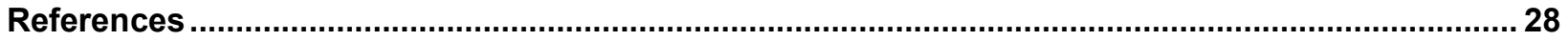




\section{List of Figures}

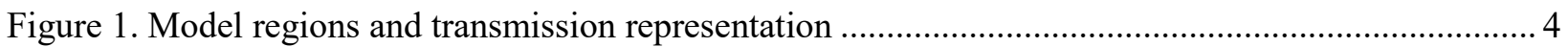

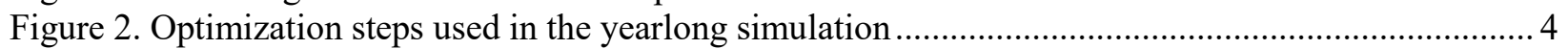

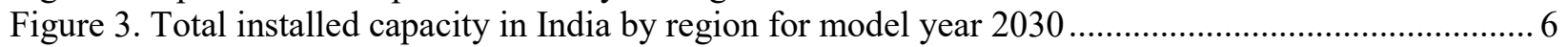

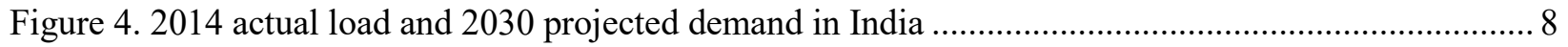

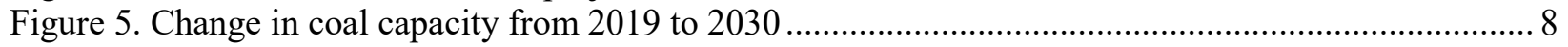

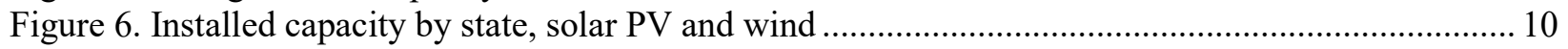

Figure 8. Annual wind and solar generation (panel A) and penetration as percent of load (panel B)

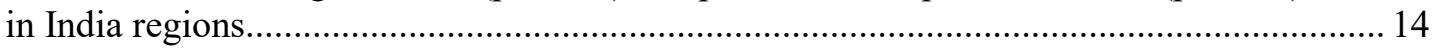

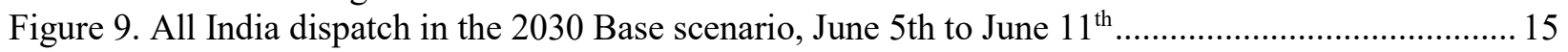

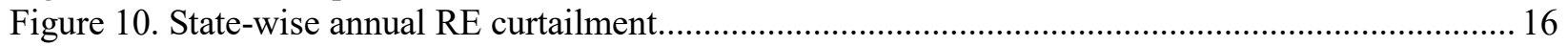

Figure 11. Plant load factor of thermal power plants .......................................................................... 16

Figure 12. Total import and export in India regions and neighboring countries in $2030 \ldots \ldots \ldots \ldots \ldots \ldots \ldots \ldots . . . \ldots 17$

Figure 13. Difference in total generation, Intra-region Expansion scenario ........................................... 19

Figure 14. Average hourly net export in Karnataka and Tamil Nadu .................................................... 19

Figure 15. Average daily interface flow across regional transmission interfaces................................... 21

Figure 16. Short run marginal cost of generation in India regions ........................................................ 22

Figure 17. Generation dispatch in the Copperplate scenario during peak India load .............................. 23

Figure 18. Hourly committed capacity and generation dispatch for three days in September,

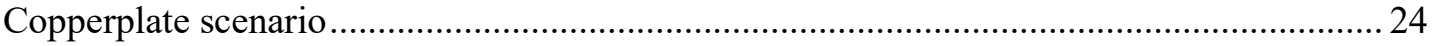

Figure 19. Distribution of peak loads by state and for all of India ..................................................... 25

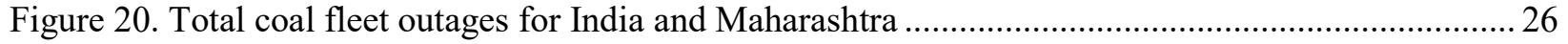

\section{List of Tables}

Table 1. Conventional Installed Generation Capacity for the 2030 Model …....................................... 7

Table 2. Operational Constraints for Thermal Plants, Average by Technology ........................................ 9

Table 3. Fleet-Wide Average Outage Rate for Thermal Plant Technologies ............................................ 9

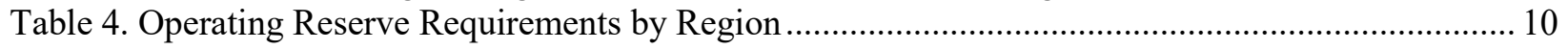

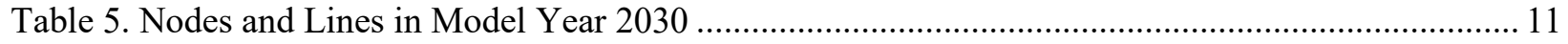

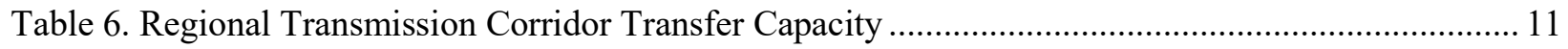

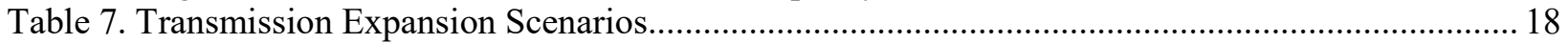

Table 8. Production Costs in Transmission Expansion Scenarios (INR Crore)....................................... 20 


\section{Introduction}

India has established several targets for renewable energy (RE) capacity growth in the coming years, most notably the target of deploying 175 gigawatts $(\mathrm{GW})$ of generation capacity from wind, solar, biomass, and small hydropower by 2022, and furthering that vision with India's Nationally Determined Contribution target of $40 \%$ renewable electricity capacity (including hydropower) by 2030 (GOI 2015). Analysis by the Central Electricity Authority (CEA) suggests that wind and solar capacity would grow by another $100 \mathrm{GW}$ from 2022 to 2027 to help achieve that target. While reaching $275 \mathrm{GW}$ of wind and solar capacity by 2027 would be a significant achievement, the combined growth of wind and solar in the 2022-27 period would average less than $20 \%$ per year compared to annual growth rates of over $30 \%$ in the last four years, with solar alone growing $82 \%$ in 2016 (MNRE 2018).

As a consequence of the targets and rapidly falling RE prices, the generation mix is changing, and the operations, planning, and regulations are similarly evolving (Shah and Buckley 2019). The CEA and the Central Electricity Regulatory Commission (CERC) recently published a number of regulations and policies aimed at improving the efficiency of the electricity system, including proposals for market reforms (CERC 2018b). Many regulations and policies aimed at improving RE integration are also being put into law (MNRE 2019). The Power System Operation Corporation Limited (POSOCO), the central and regional Independent System Operator, recently implemented a pilot on security-constrained economic dispatch, that will help lower costs of operation and make dispatch decisions more flexible, thereby easing RE integration (CERC 2019). NTPC Limited, India's central government Public Sector Undertaking focused on electricity generation, has recently studied flexible operations of its power plants, and the Central Transmission Utility is updating connectivity standards to keep pace with RE growth (CEA 2019; CERC 2018a). While many of these recent changes to improve power system operations in India are not exclusively directed at RE, they are likely to ease RE integration issues while benefiting all power system stakeholders with lower costs and increased reliability.

Given the rapid and significant changes to India's power system, the objective of this interim report is to understand the operational challenges for India's power grid in 2030. In pursuit of this objective, we have collaborated with The Energy and Resources Institute (TERI) and Climate Policy Initiative (CPI) as part of the Energy Transitions Commission (ETC). These collaborations, in addition to input from a broad stakeholder community convened by the ETC, add critical projections and feedback on assumptions for 2030 that are considered in the modeling for this report.

This report is part of a broader set of analyses under the ETC work packages, in collaboration with TERI and CPI. TERI has recently published analyses on both demand and supply through 2030, and CPI has built on these projections to analyze electricity system flexibility (Spencer and Awasthy 2019; Pachouri et al. 2019; Udetanshu et al. 2019). Through this report, the National Renewable Energy Laboratory (NREL) contributes an operational analysis of 2030 that includes spatially disaggregated, hourly commitment and dispatch modeling. Our modeling includes constraints on transmission, unit-specific costs and operating constraints, and hourly, weekly, and seasonal inter-temporal constraints that have not been previously analyzed as part of the ETC work packages. 
This report begins with a section on the methodology used for the study, including data sources, assumptions, and modeling approach. This is followed by a section on the results of the modeling, which is split into three parts: (1) results from a base scenario; (2) comparison of three scenarios designed to give insights on transmission assumptions; and (3) an analysis of periods of stress. The report concludes with a summary of key takeaways and future work. 


\section{Methodology}

Our primary tool for analyzing India's power system in 2030 is a production cost model, which simulates operations of the grid through least-cost optimization of unit commitment and economic dispatch while incorporating constraints related to transmission, limitations of each generating unit, and operational practices. ${ }^{1}$ The model attempts to balance supply and demand for every hour of 2030 to capture the temporal relationship of load, wind and solar resource availability, and other time-varying system variables such as available generation and power flow. This report establishes the inputs for a base scenario to analyze 2030 system operations and for use in ongoing work with the ETC, as well as compares several scenarios of transmission expansion to understand the sensitivity of the 2030 system operations to expectations about power flow around the country.

Several assumptions are inherent in using a typical production cost model for analyzing electric power system operations. First, only the bulk transmission network is considered, ignoring all constraints on the distribution system (typically voltages less than 11 kilovolts [kV] in India). Another assumption builds on the hourly dispatch resolution of the model - the study assumes that intra-hour variability can be met using committed resources and operating reserves. Although dispatch on India's grid is currently updated every 15 minutes, an assumption of hourly dispatch is sufficient for addressing most concerns about power system flexibility in 2030 given the high likelihood of changes to system operations and technological advancements over the next decade.

The remainder of this section details the scenarios modeled, the data incorporated, and the assumptions made when data were unavailable or incomplete.

\subsection{Modeling Grid Operations in India}

India's National Grid is a synchronous interconnection of India's contiguous states and union territories (UT) and is managed by POSOCO. However, a large portion of the management and operation of the grid is performed at the state-level in the form of state regulators, state load dispatch centers, and state generation and transmission companies. Therefore, the production cost model is built around the state-level distinctions with unique demand profiles for each state and UT, as well as transmission representation between state networks. This spatial granularity allows for insights into the state-level challenges and solutions in balancing supply and demand. Regional balancing, a key factor in maintaining reliability and coordination among India's states, is also considered through the representation of region-to-region transmission constraints in addition to state-to-state transmission.

Figure 1 illustrates the transmission representation in the model. Each solid line represents a unique transmission corridor in the simulation. See section 2.2.2.4 for a detailed description of how the transmission constraints are derived.

\footnotetext{
${ }^{1}$ We solve the unit commitment and economic dispatch with mixed-integer programming using the commercial production cost modeling software PLEXOS, by Energy Exemplar, with the Xpress-MP solver.
} 


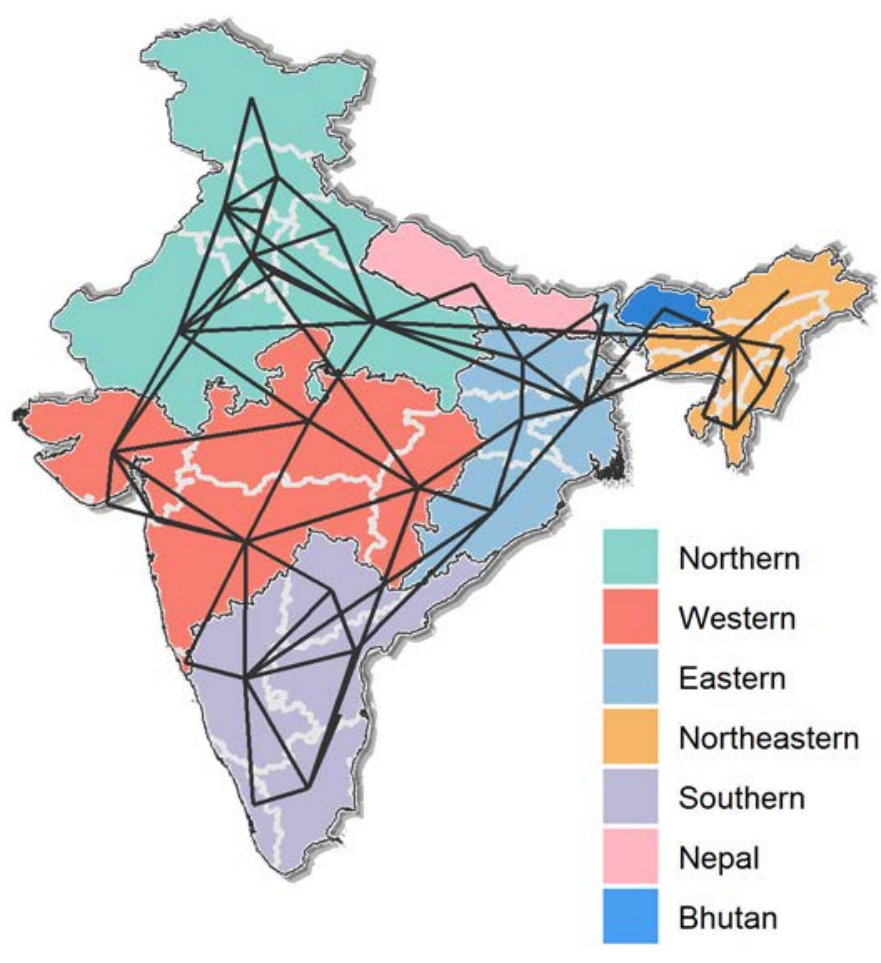

Figure 1. Model regions and transmission representation

The model is configured to capture operating decisions on multiple timescales. Generator outages are optimized over the entire operating year whereas hydropower and fuel constraints are optimized on a monthly timescale and unit commitment and economic dispatch are optimized on an hourly basis. The model is solved through a series of optimization steps, which reduce the longer constraints into manageable steps. Figure 2 illustrates the full simulation process.

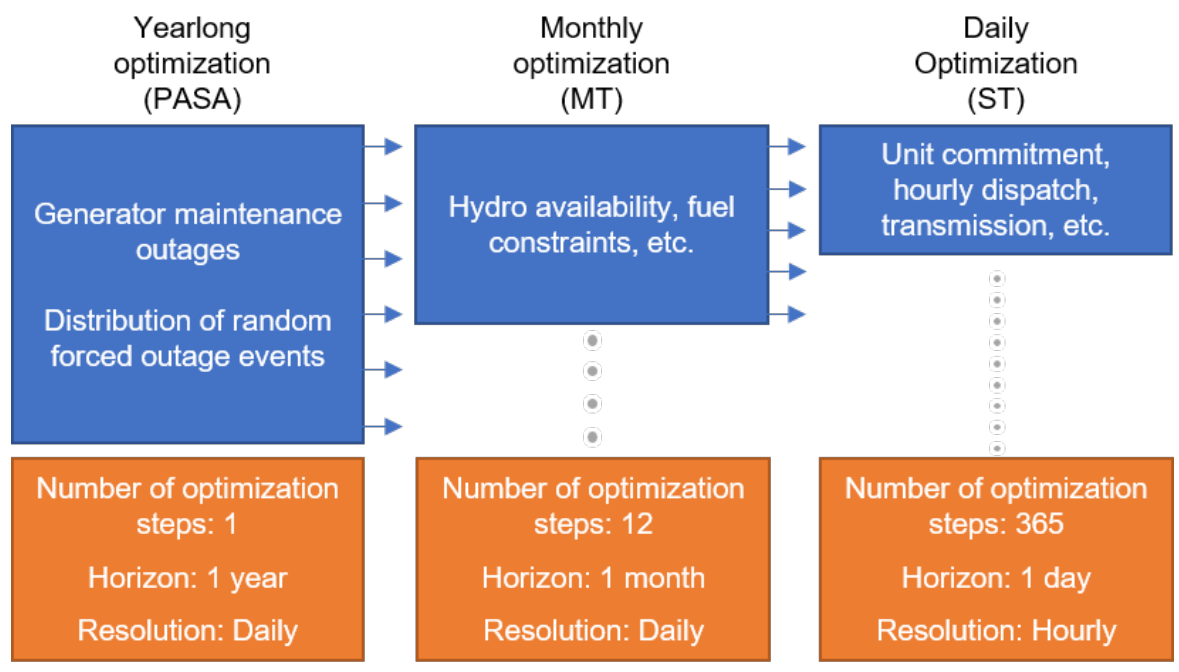

Figure 2. Optimization steps used in the yearlong simulation

First, the PLEXOS model runs an annual Projected Assessment of the System Adequacy (PASA), which aims to distribute maintenance events in an optimized manner to maintain capacity reserves throughout the year. The inputs to this step are the maintenance outage 
parameters for each generating unit. Constraints such as transmission availability, peak load, and available capacity are considered to determine the optimal schedule. Forced outages are also randomized throughout the year in the PASA to comply with the generator-wise forced outage rates. $^{2}$ Results from the yearlong PASA optimization are decomposed into shorter-term constraints and passed to the next optimization steps.

The second optimization step, the mid-term (MT), breaks up medium-term constraints from large hydro generators into steps that can be used in the short-term, 24-hour schedule. As noted in Section 2.2.2.2, large hydro is constrained by monthly energy availability and minimum generation levels. This step divides the total monthly energy available into daily targets to ensure water is available throughout each month.

The short-term (ST) schedule is a mixed-integer programming optimization of the commitment and dispatch of generators for each 24-hour period in the year. ${ }^{3}$ The ST runs each day chronologically so that decisions made in day one, such as to commit a generator, are carried through to the next optimization step in day two. The ST step closely resembles the process taken by system operators in market regions or by vertically integrated utilities to schedule the day-ahead operations. A linearized DC optimal power flow is used to model the power flows in the ST step.

\subsection{Data: Building a Grid Model of 2030}

The India database for 2030 is developed using a combination of data compiled for a previously completed study (Palchak et al. 2017), publicly available data from CEA and Power Grid, as well as inputs from TERI on electricity demand, wind and solar plant locations and capacities, and hourly wind and solar generation. The following section details the data inputs for the 2030 model.

\subsubsection{Greening the Grid - India Production Cost Model of 2022}

This study builds on a production cost model of India for 2022 that was compiled for the United States Agency for International Development (USAID) Greening the Grid (GTG) RE integration studies, completed in 2017 (Palchak et al., 2017). The goal of the GTG RE integration studies was to evaluate the operation of the grid in 2022 given the achievement of Government of India capacity targets of $175 \mathrm{GW}$ of RE. The GTG studies, which included a national level study and regional studies for the Western and Southern region, were done in collaboration with POSOCO and Lawrence Berkeley National Laboratory and reflects the input of more than 150 power system stakeholders in India. In constructing the GTG database a process of validation was undertaken to calibrate the model to historical operations in the year 2014 before adding the projected expansion to 2022. Parameters such as transmission flows across major corridors, hydro power generation restrictions, and state to state coordination were adjusted to reflect realworld constraints. Details of the model can be found in Palchak et al. (2017).

\footnotetext{
${ }^{2}$ Forced outages, while random and potentially more disruptive than maintenance outages, are still part of the schedule and are therefore not unexpected, contingency-like events.

${ }^{3}$ We configure our daily optimization steps to also include a 24-hour look-ahead period, which makes the full optimization horizon 48-hours. However, the look-ahead is only used to ensure that there is enough information for unit commitment decisions in the period of interest and is discarded when moving ahead to the next 24-hour period.
} 
While the GTG production cost model comprises a large part of the model developed for 2030, several updates were necessary. The remaining sections in 2.2 describe the details of the model and the expansion to 2030 .

\subsubsection{Building on Greening the Grid out to 2030}

Two primary tasks are required to update the 2022 GTG database to the year 2030: (1) update the existing generator and transmission system data given real system updates since GTG was completed, and (2) develop the system out to $2030 .{ }^{4}$ The bulk of the data regarding both the recent evolution of the system and the plans for system buildout come from CEA's National Electricity Plan (CEA 2018), as well as other publicly available CEA, Power Grid, and POSOCO documentation. TERI provided both the projected 2030 demand profile for the country (full 8760 hour profile) and wind and solar locations and resource profiles, detailed in Spencer et al. 2019) and Pachouri et al. 2019. ${ }^{5}$ Figure 3 shows the total installed capacity in India and by National Grid region for 2030.
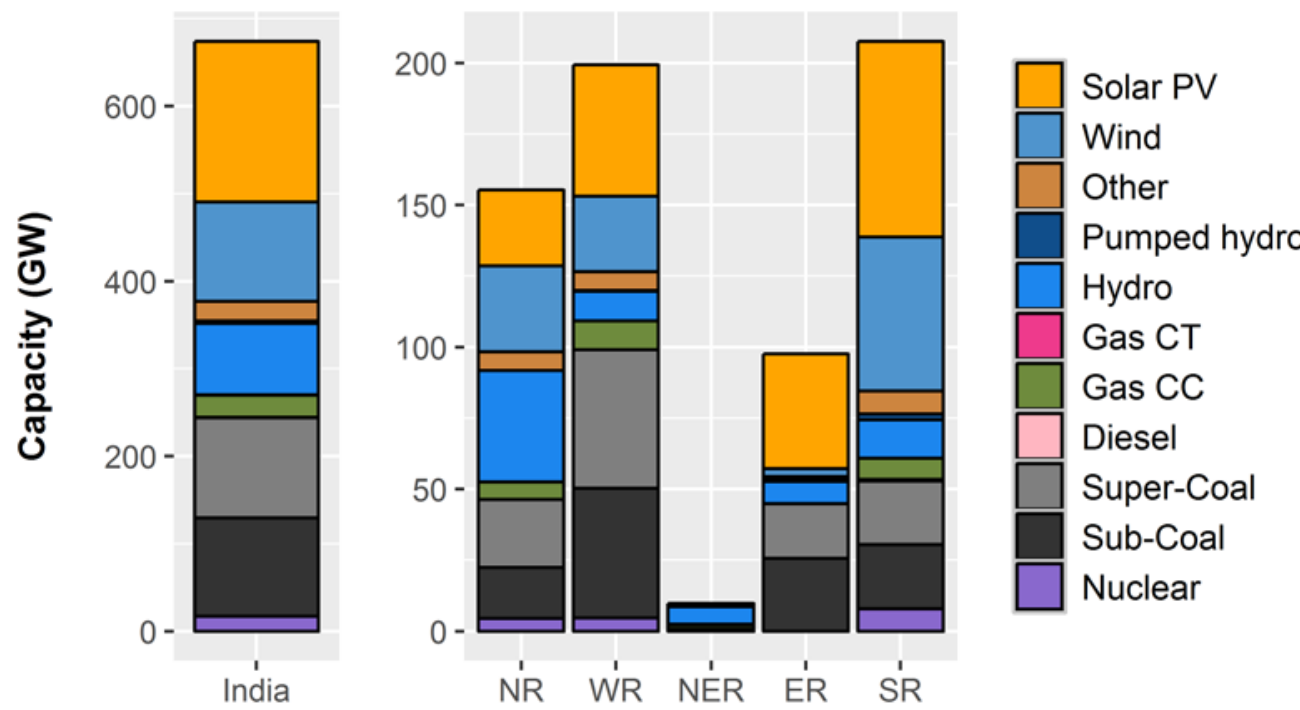

Figure 3. Total installed capacity in India by region for model year 2030

Different $y$-axis scales for all India and regional bars.

$E R=$ Eastern region, NER=Northeastern region, $N R=$ Northern region, $S R=$ Southern region, $W R=W e s t e r n$ region

The NEP is published on five-year planning cycles with the most recent edition projecting installed capacity to 2027 . To extend the 2027 projects to 2030 , we used a close approximation of TERI's Current Policy Scenario (CPS), which maintains NEP capacity growth trends for nonfossil generation of hydro and biomass. Coal, diesel, and gas capacity is assumed to be constant

\footnotetext{
${ }^{4}$ Updates to the GTG model to build a 2030 model are based mostly on the physical attributes of the power system. We did not update generation costs, which are still based on 2016 data as collected for GTG.

${ }^{5}$ TERI utilized weather data that was created by NREL for the GTG integration studies, which is based on 2014 weather.
} 
after 2027. TERI also provided wind and solar capacities and locations for the CPS, with of 184 GW solar and 113 of wind installed capacity in 2030 (Pachouri et al. 2019). ${ }^{6}$

Table 1 shows the projected conventional capacity additions and retirements out to 2030, starting from confirmed capacity figures for March 2018. The total installed capacity from coal, gas, hydro, and nuclear in 2030 is projected to reach $350 \mathrm{GW}$. Capacity additions are evaluated at the unit level to accurately represent NEP projections and to reflect the geographic distribution of generation capacity projected for 2030. Plant retirements also reflect NEP 2027 projections at the unit level. Thermal generation capacity for 2030 is closely aligned with NEP projections for 2027, with no growth assumed after 2027. Hydro capacity, however, assumes that growth continues beyond 2027 to maintain $10 \%$ of the installed capacity in 2030 , as it does in the NEP 2027 year. Biomass (not shown) also continues the same trend from 2027, maintaining 3\% of total installed capacity and growing to $22.6 \mathrm{GW}$ by 2030 .

Table 1. Conventional Installed Generation Capacity for the 2030 Model

\begin{tabular}{|l|c|c|c|c|c|c|}
\hline & Diesel & GT-Gas & Hydro & Nuclear & Coal & Total \\
\hline $\begin{array}{l}\text { CEA values as of } \\
\text { March 2018 (source: } \\
\text { data provided by CEA) } \\
\text { plus NEP additions } \\
\text { 2017-2027 (Chapter 5) } \\
\text { (CEA, 2018) }\end{array}$ & 701.6 & $25,635.5$ & $80,354.7$ & $16,980.0$ & $278,388.6$ & $402,060.4$ \\
\hline $\begin{array}{l}\text { NEP retirements } \\
\text { 2017-2027 (Chapter 5) } \\
\text { (CEA, 2018) }\end{array}$ & 177.0 & & & $51,798.0$ & $51,975.0$ \\
\hline $\begin{array}{l}\text { Final installed } \\
\text { capacity for 2030* }\end{array}$ & 701.6 & $25,518.5$ & $80,354.7$ & $16,980.0$ & $226,740.6$ & $350,295.4$ \\
\hline
\end{tabular}

* Discrepancies exist between the CEA installed capacity projections for 2027 and our final installed capacity. This is due to slight differences in plant-wise capacity that we inherited from the GTG database (based on direct input from POSOCO and other stakeholders).

\subsubsection{Demand}

Every state and Union Territory (UT) connected to India's National Grid is represented in the model with a unique hourly demand profile for 2030. The hourly profiles are based on actual demand for 2014, with projections to 2030 provided by TERI (Spencer and Awasthy 2019). Figure 4 shows the hourly actual demand for all India in 2014 and the hourly demand forecast for 2030. TERI's projected national peak demand is $348 \mathrm{GW}$ based on a $6.8 \%$ compound annual growth rate from 2014 (TERI's base growth scenario).

\footnotetext{
${ }^{6}$ Wind and solar capacities are broadly in line with TERI's CPS, although adjustments were made throughout the scenario design. Our model development timeline was not sequenced with TERI's scenario design, so some small discrepancies exist between TERI's published results and the numbers used for this study, accounting for about $9 \%$ less wind and solar capacity. These numbers also exclude capacities for Andaman and Nicobar Islands, which are not part of the model used for this study.
} 


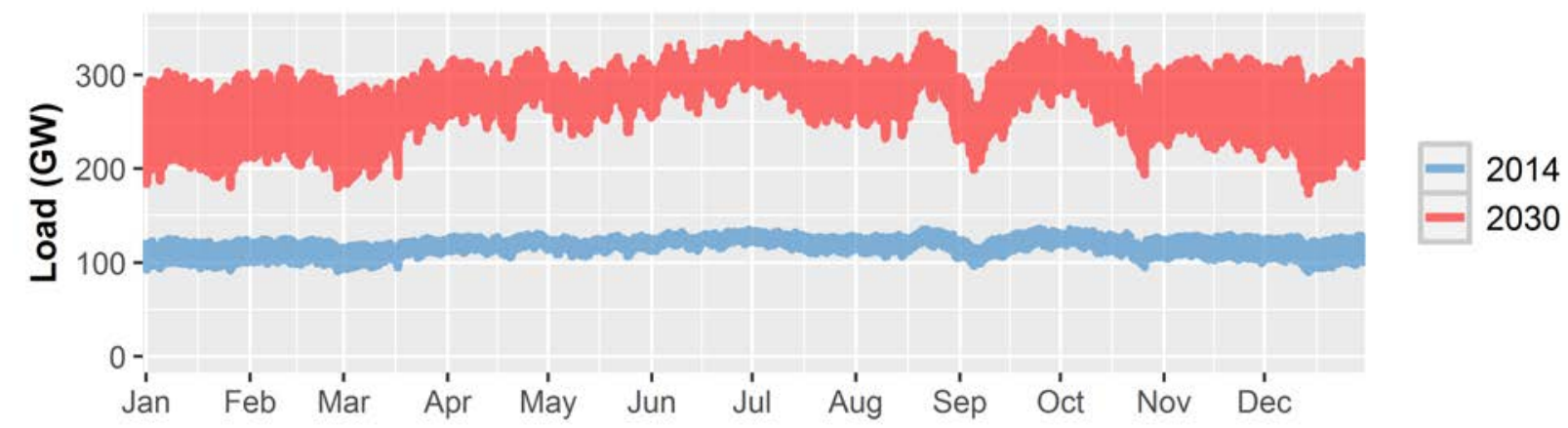

Figure 4. 2014 actual load and 2030 projected demand in India

In addition to changes in peak demand, the shape of the demand was also adjusted using the load factor projections from CEA's $19^{\text {th }}$ Electric Power Survey (CEA 2017). Following trends from recent years, CEA projects that national-level load factors will continue to decrease - from $84.08 \%$ in 2016 to $78.23 \%$ in 2027 , meaning greater disparity between daily averages and daily peaks. The 2027 load factor adjustment is used in TERI's national demand profile for 2030.

\subsubsection{Fossil and Hydro}

The thermal power plant fleet represents planned capacity additions and retirements based on the $12^{\text {th }}$ NEP (plans out to 2027, CEA 2018). Figure 5 shows the state-wise change in coal capacity from January 2019 and the model year 2030. Madhya Pradesh and Odisha have the largest increases in coal capacity while several states, most significantly in the Northern region, have small decreases in coal plant capacity to 2030.

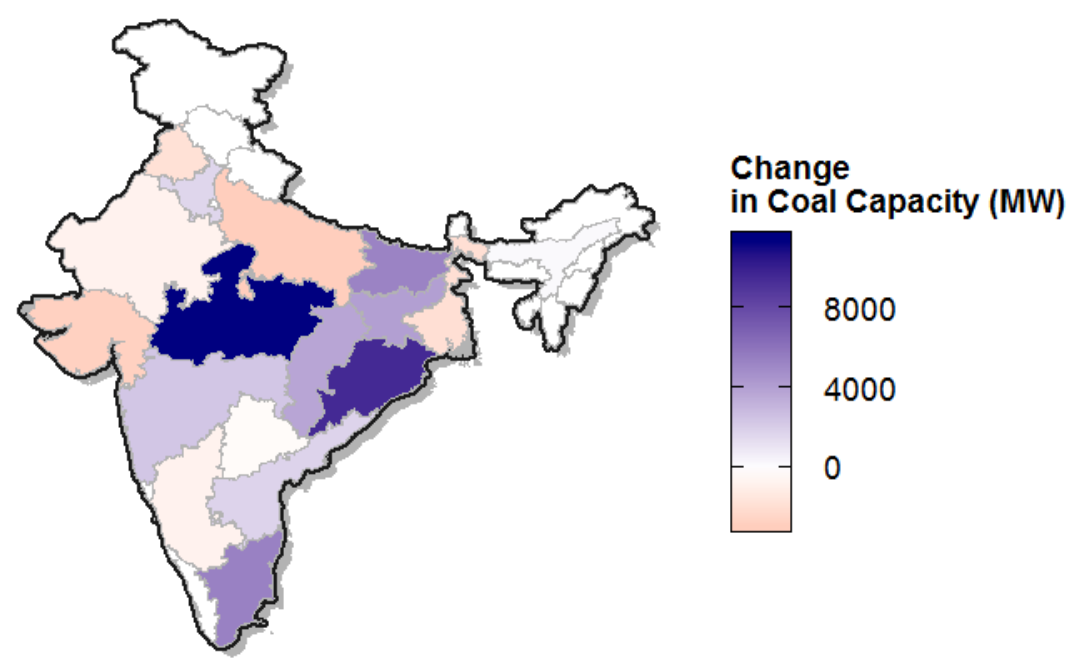

Figure 5. Change in coal capacity from 2019 to 2030

Fossil-fueled thermal plants are represented in the model with unit-level constraints including minimum stable level, ramp rate, minimum up and down time, and start-up and shut-down costs. Partial-load heat rates are derived from unit-level costs and CERC three-part heat rate norms, which are inherited from the GTG database. New capacity additions beyond 2022 are given average parameter values based on technology type and state or region, depending on data availability. Table 2 presents national average values of key operational constraints for thermal plant technologies. 
Table 2. Operational Constraints for Thermal Plants, Average by Technology

\begin{tabular}{|l|c|c|c|}
\hline Technology & $\begin{array}{c}\text { Minimum Stable Level } \\
\text { (\% of installed capacity) }\end{array}$ & $\begin{array}{c}\text { Max Ramp Up } \\
\text { (\% of installed } \\
\text { capacity) }\end{array}$ & $\begin{array}{c}\text { Minimum Up/Down } \\
\text { Time (hours) }\end{array}$ \\
\hline Gas CC & $50 \%$ & $3 \%$ & 8 \\
\hline Gas CT & $60 \%$ & $3 \%$ & 2 \\
\hline Nuclear & $100 \%$ & $0.5 \%$ & 0 \\
\hline Sub-Coal & $55 \%$ & $1 \%$ & 24 \\
\hline Super-Coal & $55 \%$ & $1 \%$ & 24 \\
\hline
\end{tabular}

Gas generator operations in India are often dictated by natural gas fuel availability. The GTG database used a combination of optimized and forced outages to represent times of the year when natural gas is not available for electricity generation in 2022. For 2030, we assume that more information will be available to schedule gas delivery for the power sector, such that gas generator outages are optimized to ensure availability during peak load periods. But, the total availability of gas and the frequency of gas outages is maintained from GTG, with an average availability factor of $57 \%$. Table 3 shows the average outage rate (including both maintenance and forced outages) for each thermal technology in the 2030 model.

Table 3. Fleet-Wide Average Outage Rate for Thermal Plant Technologies

\begin{tabular}{|c|c|}
\hline Technology & $\begin{array}{c}\text { Average Plant } \\
\text { Outage Rate }\end{array}$ \\
\hline Gas CC & $44 \%$ \\
\hline Gas CT & $30 \%$ \\
\hline Nuclear & $28 \%$ \\
\hline Sub-Coal & $15 \%{ }^{*}$ \\
\hline Super-Coal & $12 \% *$ \\
\hline
\end{tabular}

Hydro generators can be challenging to represent in production cost models because their operation is often dictated by authorities outside the power system for purposes such as irrigation, drinking water, or ecological health. Using multiple years of historical generation data, we identified typical operations of individual hydro plants and used model parameters to mimic these real-world constraints. Four different types of hydro plants are represented in the model: run-of-river, pondage (run-of-river with small storages at the head), reservoir storage, and pumped-hydro storage. For plants with storage (reservoir or pondage), daily or monthly energy limits as well as minimum generation limits capture the limited availability of water and the need to release water for irrigation or other purposes. Run-of-river plants are constrained by hourly energy availability. Pumped-storage plants are fully dispatchable up to their nameplate capacity as generators but are required to pump the same amount of energy as they generate, plus efficiency losses of $25 \%$, during each day.

Operating reserves are captured in the model through the provision of spare capacity in the commitment and dispatch schedule. The total regional reserve requirement is equal to the proposed CERC secondary and tertiary reserve requirements, which is equivalent to the largest 
capacity unit in each region plus half of the largest capacity unit within each state. This is held in the model as a single reserve requirement. Table 4 shows the magnitudes for each region.

Table 4. Operating Reserve Requirements by Region

\begin{tabular}{|l|c|}
\hline \multicolumn{1}{|c|}{ Region } & Reserves Held (MW) \\
\hline Eastern & 2,160 \\
\hline Northeastern & 363 \\
\hline Northern & 2,224 \\
\hline Southern & 2,722 \\
\hline Western & 2,332 \\
\hline
\end{tabular}

\subsubsection{Renewable Energy}

$\mathrm{RE}$ is represented in the model with high spatial and temporal granularity, using the same resource data (wind speed, solar irradiance, etc.) from GTG, but with site selection performed by TERI to reach the $275 \mathrm{GW}$ capacity target. Wind resource availability has spatial granularity of $3 \times 3 \mathrm{~km}^{2}$, and solar $10 \times 10 \mathrm{~km}^{2}$. Geographic land-use filters were used to designate land areas as suitable for development and sites were chosen based on those with the highest annual capacity factor resulting in a state-wise installed capacity shown in Figure 6.

Solar PV
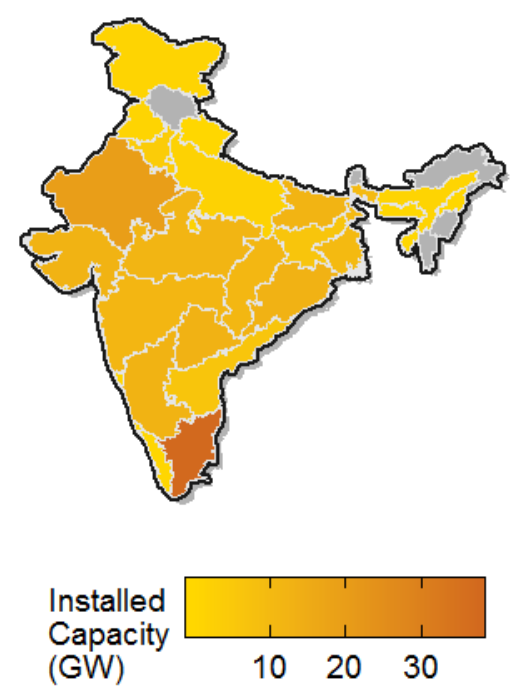

Wind
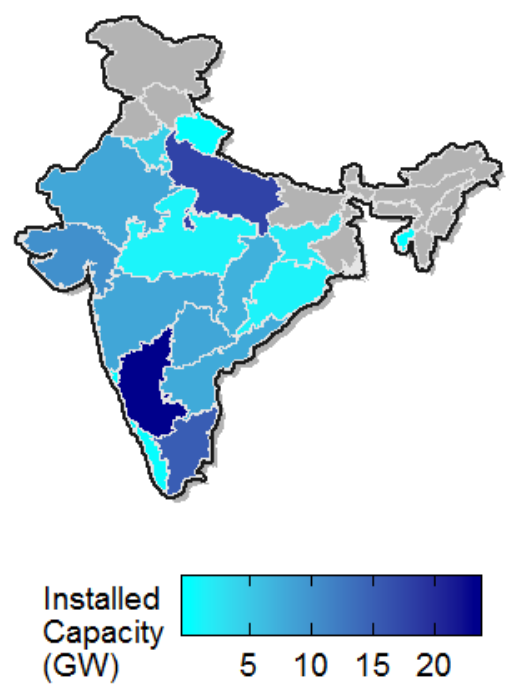

Figure 6. Installed capacity by state, solar PV and wind

Gray color indicates zero installed capacity

Inputs to the production cost model require hourly renewable energy generation profiles, which were produced using NREL's System Advisor Model and typical wind power curves. ${ }^{7}$

\footnotetext{
${ }^{7}$ Techniques and inputs for developing hourly wind and solar generation profiles for each selected location are the same as described in Appendix A of Palchak et al. (2017). All wind turbines are assumed to have a 100m hubheight.
} 


\subsubsection{Transmission}

The 2030 India transmission network is based on the network developed for the GTG database, although key differences are present in the way the transmission system is constrained. Transfer capacity between India's regions is scaled up significantly to represent transmission network upgrades and expansion through 2030. Additionally, new international connections have been considered in the model, which is detailed in the Section 2.2.2.5. Table 5 summarizes key characteristics of the transmission network model.

Table 5. Nodes and Lines in Model Year 2030

\begin{tabular}{|c|c|c|}
\hline Number of Nodes & \multicolumn{2}{|c|}{37} \\
\hline Number of inter-state lines & 627 AC lines & 24 DC lines \\
\hline Number of international lines & 9 AC lines & 1 DC line \\
\hline
\end{tabular}

Transmission constraints are represented by state-wise and region-wise transfer capacities. We assume sufficient transmission capacity within states to enable unconstrained power flows on lines that do not cross state boundaries (same assumption as the GTG national study (Palchak et al. 2017)). Transfer capacities between regions in 2030 are based on thermal ratings of existing and planned transmission lines through 2022. We do not add lines in 2030 due to a lack of data. Instead, we allow transfers up to existing thermal limits to represent additional transmission capacity that may be added until 2030. This approach maintains the existing electrical properties of the network while allowing higher levels of interchange than operating practices would currently allow. Table 6 compares region-wise transfer limits in the model with current Available Transfer Capability (ATC) (Power Grid Corporation of India 2019). ${ }^{8}$

Table 6. Regional Transmission Corridor Transfer Capacity

\begin{tabular}{|l|c|c|}
\hline \multicolumn{1}{|c|}{ Corridor } & $\begin{array}{c}\text { Available Transfer } \\
\text { Capability in 2019 } \\
\text { (MW) }\end{array}$ & $\begin{array}{c}\text { Assumed Transfer } \\
\text { Capacity in 2030 (MW) }\end{array}$ \\
\hline Eastern - Northeastern & 1520 & 3656 \\
\hline Eastern - Northern & 6100 & 21022 \\
\hline Eastern - Southern & 3850 & 7600 \\
\hline Eastern - Western & Not Reported & 17681 \\
\hline Western - Northern & 17700 & 33568 \\
\hline Western - Southern & 7300 & 22687 \\
\hline
\end{tabular}

\footnotetext{
${ }^{8}$ ATCs are limits to power flow on critical transmission corridors. POSOCO and Power Grid calculate these limits with AC power flow models and will limit system flows based on modeling and other system characteristics to maintain security and reliability on the power system.
} 


\subsubsection{International Interconnections}

Interconnections to Nepal, Bhutan, and Bangladesh are represented in the production cost model. Nepal is represented with a single node on the transmission network, which has connections to both Uttar Pradesh and Bihar, and has unit-wise representation of projected generation for 2022 according to the Nepal Electricity Authority and NREL analysis. ${ }^{9}$ Total generation capacity in Nepal is $2886 \mathrm{MW}$, with $2839 \mathrm{MW}$ of hydro and a small amount of diesel and fuel oil. The total transfer capability (thermal line limits) between Nepal and India is 1993 MW.

Bhutan is represented in the model with a single transmission node and a transfer capacity of $2300 \mathrm{MW}$ to Assam and $6481 \mathrm{MW}$ to West Bengal. The Bhutan generation capacity is assumed to be $4482 \mathrm{MW}$, which includes the generators from the NEP (totaling $4356 \mathrm{MW}$ ), as well as one additional hydro plant that is currently fully operational. The hydro generators in Bhutan are constrained by daily energy limits and minimum generation limits according to historical exports to India. ${ }^{10}$

Bangladesh is represented with a constant $1000 \mathrm{MW}$ of load in anticipation of potential upgrades to the existing network, which is connected to India via a DC tie to West Bengal (JTT 2016).

\footnotetext{
${ }^{9}$ For a more complete explanation of the Nepal representation see McBennett et al. 2019 from which we inherited the "Base Buildout" scenario. Additional projections for Nepal beyond the capacity envisioned for 2022 in McBennett et al. are beyond the scope of this study. The demand in Nepal is also captured in the model according to Nepal Electricity Authority projections for 2022. Projections for Nepal beyond 2022 were beyond the scope of this study.

${ }^{10}$ Historical imports from Bhutan were scaled according to new 2030 plant capacities such that daily and seasonal trends were maintained, as well as plant-wise capacity factors, but total energy reflects the new capacity. Historical import data was part of the GTG model.
} 


\section{Operation of India's Grid in 2030}

The model results show how generators meet demand at least-cost while upholding the system constraints, such as the ability of power to flow through the transmission system or the availability of generators. The remainder of Section 3 summarizes these results with a focus on the following questions:

1) Is the system able to balance (i.e., meet demand) every hour of the year?

2) How do conventional and renewable energy sources, combined with transmission constraints, operate to meet demand?

3) How does power flow around the country?

4) Are certain periods of the year particularly challenging from an operational or reliability perspective?

To help answer these questions we analyze the CPS, or Base Case, in detail. ${ }^{11} \mathrm{We}$ also look at different levels of transmission on key region-to-region and state-to-state corridors to better understand how transmission constraints may impact the results. Finally, we examine generator availability and the impacts of generator maintenance scheduling on system reliability.

\subsection{Base Case Results}

This section reviews key modeling results for the Base Case, which uses the operational assumptions, constraints, transmission and generation capacity mix described in section 2 .

\subsubsection{Generation Dispatch}

Annual generation from India in the 2030 model year is $2385 \mathrm{TWh}$, with $59 \%$ generated by coal, followed by wind and solar generating $22 \%$, and hydro $9 \%$. Figure 7 shows the monthly generation mix in 2030. Energy generation from wind and solar is $518 \mathrm{TWh}$ in the 2030 model year, with relatively large variations between months. October has the lowest variable renewable generation month with 33.4 TWh, with the highest being July with 60.0 TWh. The seasonal trend in renewable generation roughly coincides with energy demand, except for October.

\footnotetext{
11 The Base Case uses the "Regional Coordination" scenario from GTG for the transmission flow hurdle rates, which assumes that states within a region have relatively good coordination for economic dispatch (Palchak et al. 2017).
} 


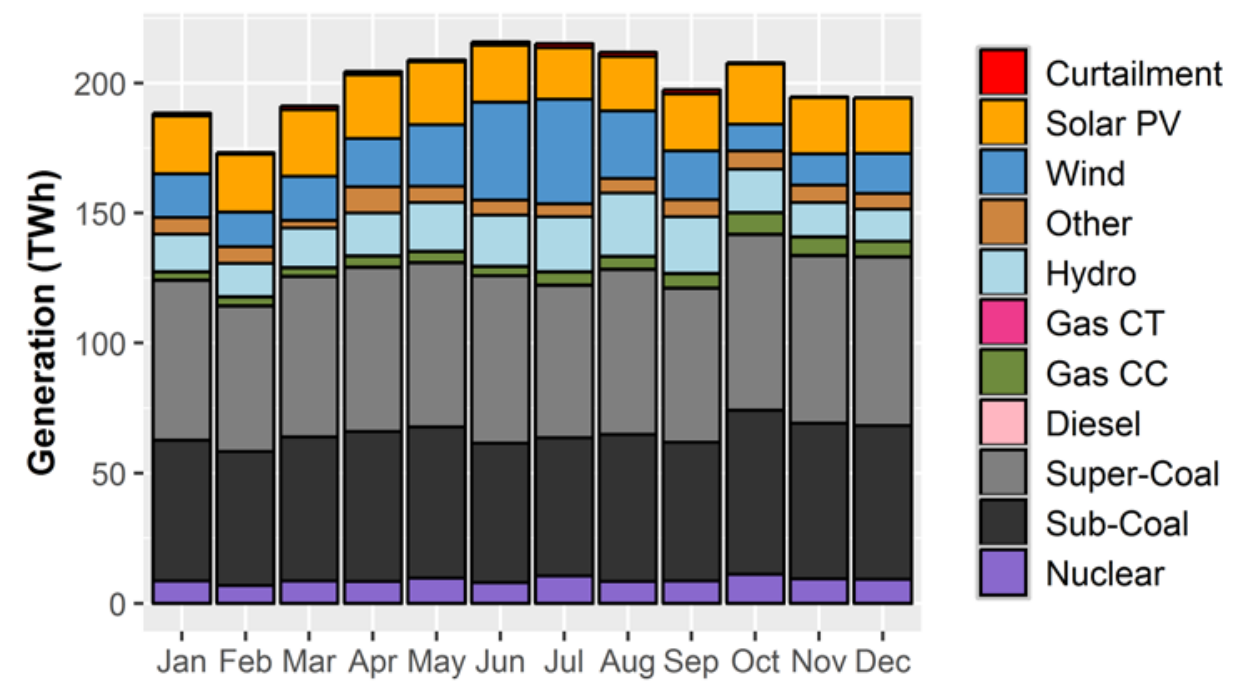

Figure 7. Total monthly generation by technology in the 2030 Base Scenario

Compared to planning for 2022, which focuses on growth of RE in the Western and Southern region, TERI's analysis for $2030 \mathrm{RE}$ distributes the growth more evenly around the country as the total capacity needs grow, which impacts operations in those regions (Power Grid Corporation of India 2012). Figure 8 shows the annual generation and penetration of wind and solar energy in India's National Grid regions. The Eastern region reaches $20 \%$ annual solar penetration of demand, and the Northeast region reaches over 5\%. The Southern region has the highest overall variable RE generation and annual penetration with wind and solar generating $229 \mathrm{TWh}$, or $36 \%$ of annual Southern region demand. The all-India peak instantaneous RE penetration reaches $56 \%$ at noon on June $13^{\text {th }}$.
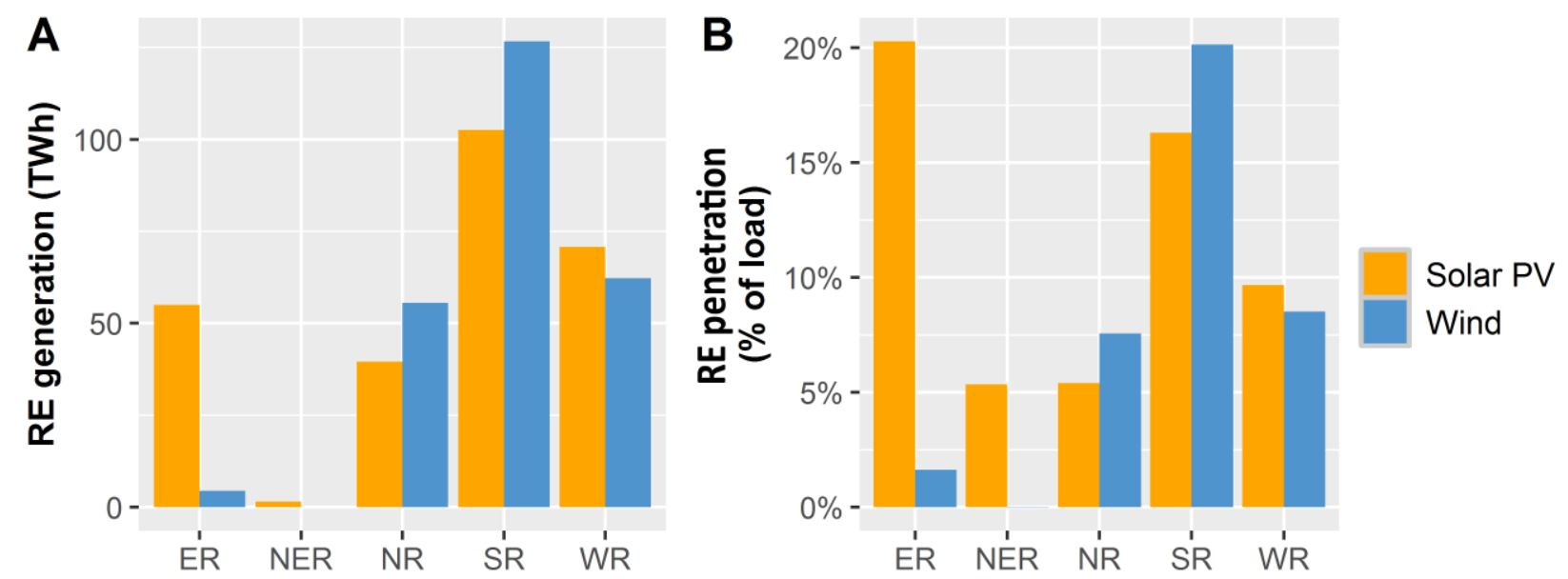

Figure 8. Annual wind and solar generation (panel A) and penetration as percent of load (panel B) in India regions

$E R=$ Eastern region, $N E R=$ Northeastern region, $N R=$ Northern region, $S R=$ Southern region, WR=Western region 
With these penetrations of wind and solar some of the available generation is not able to be used and is curtailed. Curtailment occurs when available wind and/or solar generation is not used due to system constraints, such as transmission availability or minimum generation levels of committed thermal plants. Annual variable renewable energy curtailment is $12.4 \mathrm{TWh}$ or $2.3 \%$ of available RE. Curtailment is highest in the monsoon months, coinciding with high-wind and occuring mostly during daytime hours when both wind and solar are available. Figure 9 shows the generation dispatch for one example week, June $5^{\text {th }}-$ June $11^{\text {th }}$, with RE curtailment shown in red. Throughout the year, curtailment only occurs during the middle of the day when both wind and solar are generating.

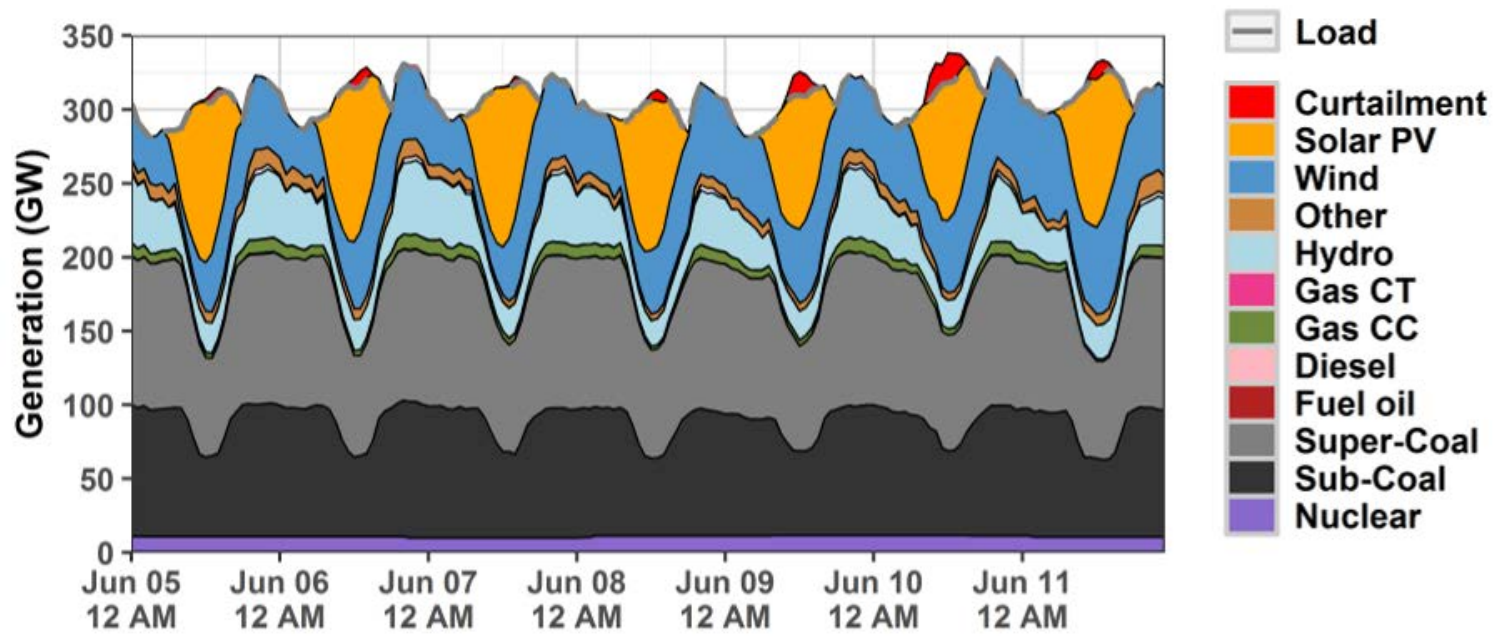

Figure 9. All India dispatch in the 2030 Base scenario, June 5 th to June $11^{\text {th }}$

While national-level annual curtailment is low, certain states experience high levels of curtailment relative to available RE generation, from $16 \%$ in Odisha to $44 \%$ in Punjab. ${ }^{12}$ Total RE curtailment is highest in Odisha, Karnataka and Tamil Nadu. Figure 10 shows total curtailment in TWh by state. The Southern and Eastern region states with high levels of curtailed $\mathrm{RE}$ are also states with highest RE generation. Notably, the Southern region is a net energy importer on an annual basis (see Figure 12). However, during midday high-RE periods, transmission constraints between states within Southern region prevent power wheeling that would otherwise enable the Southern region to export excess RE generation to the Western and Northern regions. Northern region states such as Rajasthan and Punjab also experience curtailment during the middle of the day, when transmission constraints prevent export of power to neighboring NR states with high electricity demand (i.e., Delhi and Haryana). The relationship between curtailment and state-to-state transmission is explored further in Section 3.2.

\footnotetext{
${ }^{12}$ As mentioned in section 2.2.2.4, the transmission and generation expansion were not optimized. It is likely that curtailment levels seen in Punjab would not occur as transmission would be built to evacuate it. Also, the installed capacity in Punjab is relatively small, representing less than $0.3 \%$ of the total installed RE capacity.
} 


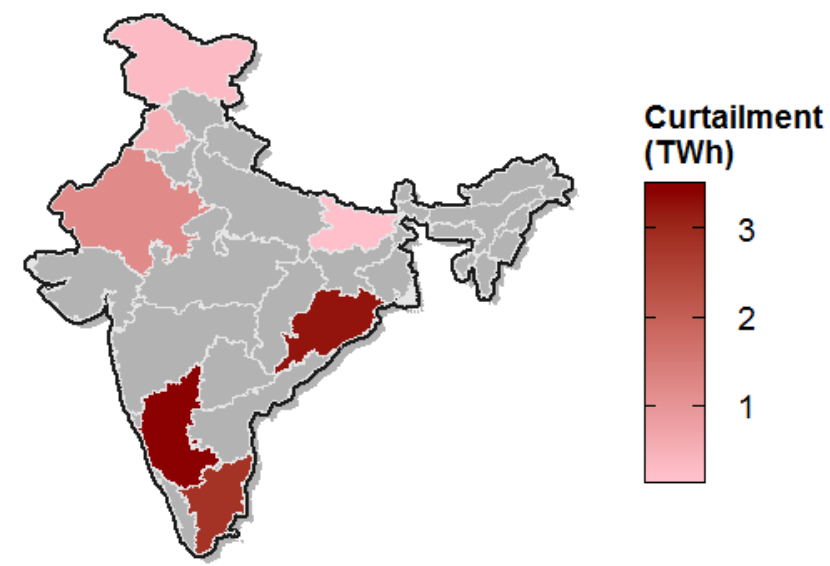

Figure 10. State-wise annual RE curtailment

Among thermal power plant technologies, coal-fired power plants have the highest average plant load factor (PLF) of 70\%. Figure 11 shows the PLFs for conventional generators by technology. Plant outages, operating constraints, and thermal plant efficiency are the primary factors that impact power plant PLFs. For example, while all sub-critical coal plants have the same annual outage rate, some plants have PLFs that are far below the fleet-wide average, with a handful of plants that operate below 25\% PLF. This is because lower-efficiency plants (i.e., plants that burn more fuel per unit of electricity generation) as well as plants with higher variable costs from O\&M and fuel prices, are dispatched less compared to more efficient power plants with lower operating cost. For nuclear power plants, high PLFs are a result of physical constraints that dictate minimum up/down time, ramp rates and start-up time, which dictate how these plants can be dispatched.

Gas plants have relatively low PLFs due to high plant outages associated with gas availability, as described in Section 2.2.2.2, as well as higher variable costs when compared with other thermal technologies.

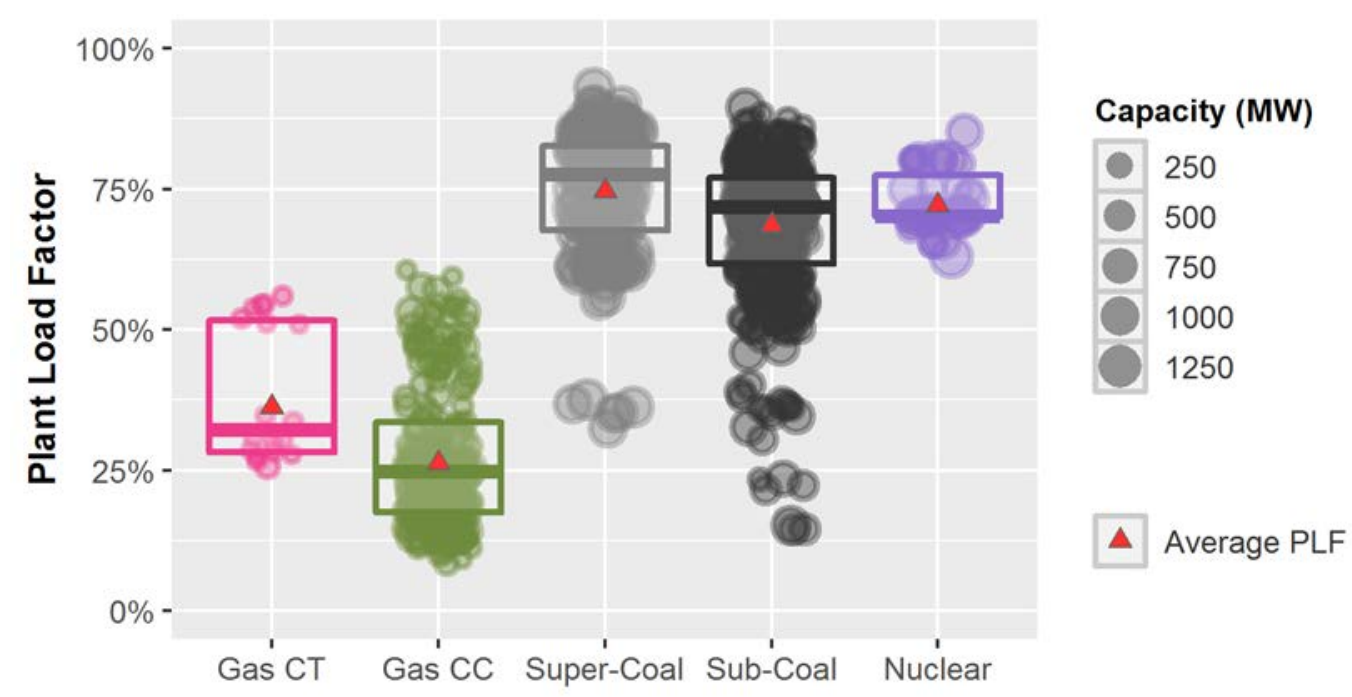

Figure 11. Plant load factor of thermal power plants

Each circle represents one power plant and is sized to the nameplate capacity. The box encompasses the middle $50^{\text {th }}$ percentile of plants and the middle line represents the median. 


\subsubsection{Imports and Exports}

Figure 12 depicts annual energy imports and exports in the National Grid regions. The Northern region continues to be a large importer in 2030 with annual imports of $522 \mathrm{TWh}$, while the Western region has 398 TWh of annual exports. The Northeastern region has close to zero net energy trade because limited hydro resources are exported during peak hours to serve demand in the Northern region and conserved during low-load periods, when imports from the Eastern region are used to cover local demand.

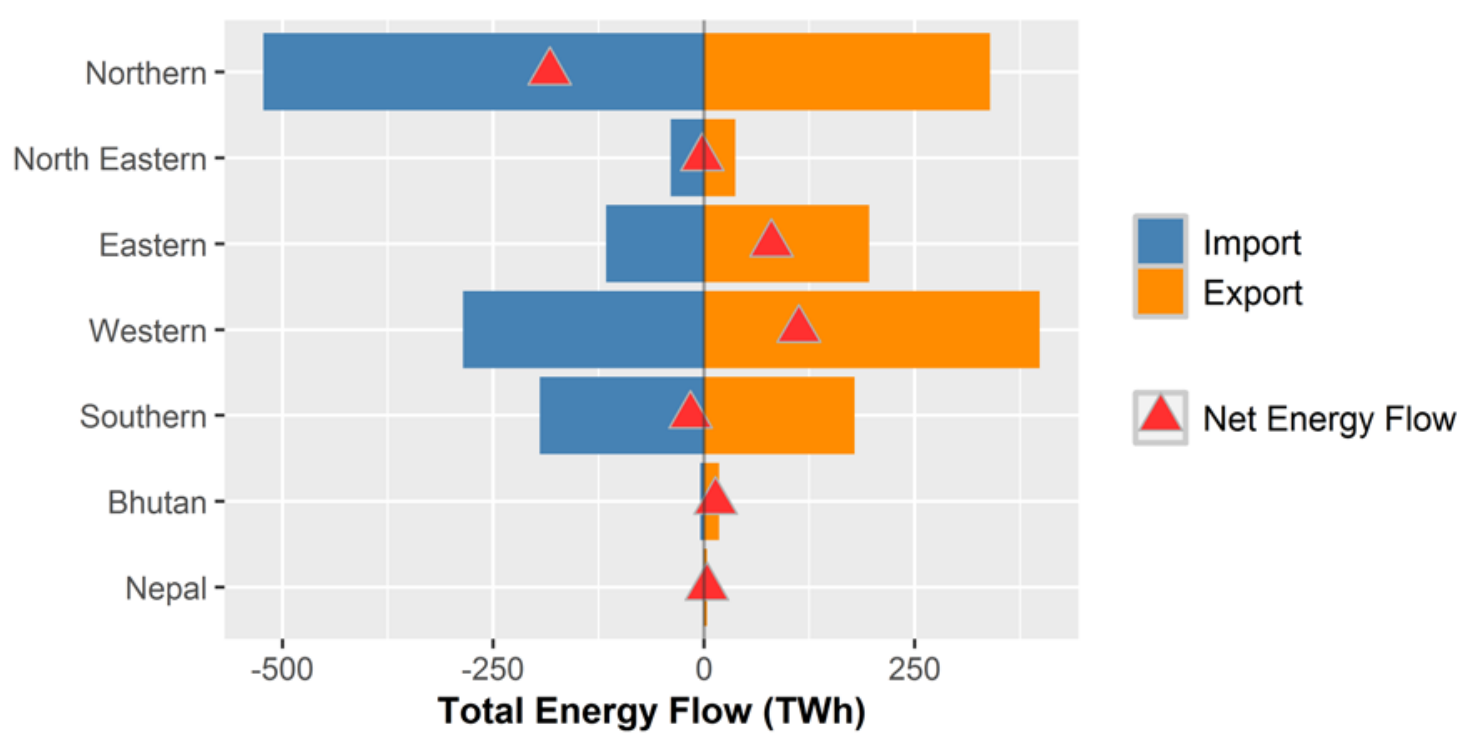

Figure 12. Total import and export in India regions and neighboring countries in $\mathbf{2 0 3 0}$

\subsection{Transmission Scenarios}

We examined two additional scenarios of transmission system expansion by 2030 to better understand how the assumed transmission network is affecting results and gain insight into how power would flow given a network with unlimited capacity. ${ }^{13}$ Transmission is of particular interest in this interim report because transmission capacity expansion is complicated to model, and lessons learned from these scenarios could impact decision on transmission assumptions for future work.

\footnotetext{
${ }^{13}$ While there are several valid assumptions to build scenarios around, transmission is of particular interest in this interim report because transmission capacity expansion is complicated and time consuming to model. Lessons learned from these scenarios will impact transmission assumptions for future work.
} 
Table 7. Transmission Expansion Scenarios

\begin{tabular}{|l|l|l|}
\hline \multirow{4}{*}{$\begin{array}{l}\text { Increased } \\
\text { network } \\
\text { capacity }\end{array}$} & $\begin{array}{l}\text { Transmission } \\
\text { Scenario }\end{array}$ & Description \\
\cline { 3 - 3 } & $\begin{array}{l}\text { Base Case } \\
\text { (CPS) }\end{array}$ & $\begin{array}{l}\text { State-wise and region-wise interfaces are enforced based } \\
\text { on existing thermal line limits }\end{array}$ \\
\cline { 3 - 4 } & $\begin{array}{l}\text { Intra-region } \\
\text { Expansion }\end{array}$ & $\begin{array}{l}\text { State interfaces are not enforced, region-wise interfaces } \\
\text { are enforced based on existing thermal line limits } \\
\text { Intra-region Expansion removes the potential for } \\
\text { congestion within each of the five National Grid regions }\end{array}$ \\
\hline & Copperplate & No transmission constraints \\
\hline
\end{tabular}

The transmission scenarios in Table 7 represent a system with varying total transmission capacity but maintaining system characteristics (line impedance) by running a DC power flow in the production cost model. This approach maintains relative relationships between corridors; however, some key characteristics of increased capacity may be missed, such as increased system losses and the potential for new transmission corridors being built by 2030 . Future work may involve more optimal transmission expansion scenarios.

\subsubsection{Transmission Scenario Results}

Compared with the Base Case, the Intra-region Expansion scenario has significantly less curtailment; however, small levels of RE curtailment remain economic. Total curtailment is reduced from $2.3 \%$ to $0.9 \%$, representing $7.9 \mathrm{TWh}$ in additional wind and solar energy used to serve electricity demand. Figure 13 shows the total generation difference by region in the intraregion expansion scenario. These curtailment reductions correlate with increased state-to-state flows during high-RE periods. This is illustrated in Figure 14, which shows the average hourly pattern of net exports in the high-RE states of Tamil Nadu and Karnataka. Increased transmission capacity enables both states to export more midday when solar resources are highest.

\footnotetext{
${ }^{14}$ The Copperplate scenario increases dispatch coordination according to the "National Coordination" hurdle rates from GTG, while the Base Case and Intra-region Expansion scenarios use the "Regional Coordination" hurdle rates (Palchak et al. 2017). Therefore, the Copperplate scenario represents an idealized version of transmission utilization both in terms of transmission capacity and dispatch decisions.
} 


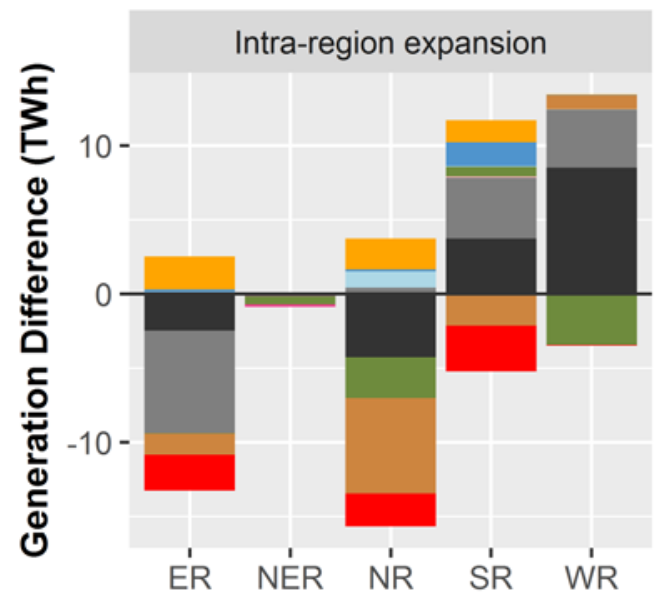

Curtailment

Solar PV

Wind

Other

Hydro

Gas CT

Gas CC

Diesel

Fuel oil

Super-Coal

Sub-Coal

Nuclear

Figure 13. Difference in total generation, Intra-region Expansion scenario

Difference is the total change relative to the Base Case scenario. ER=Eastern region, NER=Northeastern region, $\mathrm{NR}=$ Northern region, $\mathrm{SR}=$ Southern region, $\mathrm{WR}=$ Western region
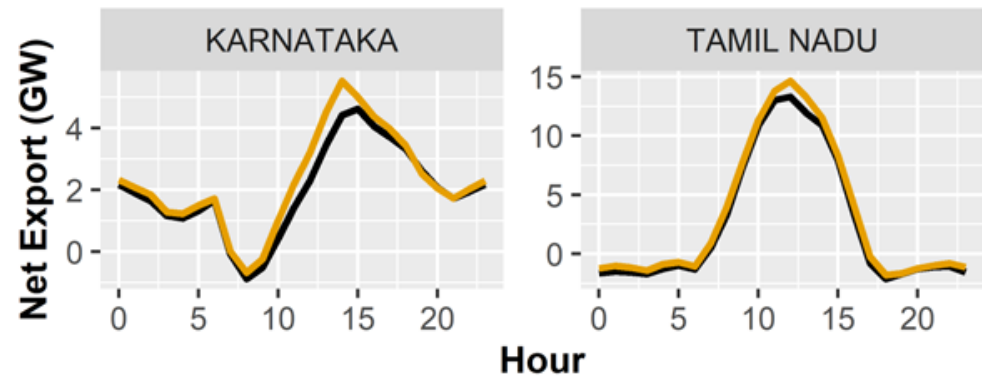

Hour

\section{Base - Intra-region expansion}

Figure 14. Average hourly net export in Karnataka and Tamil Nadu

Total annual production costs are reduced by INR 8385 crore (USD 1.3 billion), ${ }^{15}$ or about $2 \%$, with Intra-region Expansion due to lower fuel costs for coal- and gas-fired power plants. Some coal and gas generation is replaced by low-cost RE that was not curtailed. Additionally, some coal generation in Eastern and Northern regions is replaced by lower-cost coal generation in Southern and Western regions.

To enable an optimal flow of power across the inter-state network as envisioned in the transmission expansion scenarios, coordination among State Load Dispatch Centers and the Regional Load Dispatch Centers is needed to schedule seasonal, daily, and intra-day flows across key transmission corridors. Table 8 illustrates production costs by category for each scenario. Most of the operational benefit of increased transmission happens by expanding intra-regional links in the Intra-region Expansion scenario. Increased costs for startups and shutdowns for thermal generation result from a more efficient dispatch, allowing plants in neighboring states to

\footnotetext{
${ }^{15}$ We used a conversion rate of INR 65 to USD 1.
} 
share resources and therefore turn off plants more often. ${ }^{16}$ Additional cycling costs, however, are offset by system-wide production cost savings due to reduced fuel consumption.

Table 8. Production Costs in Transmission Expansion Scenarios (INR Crore)

\begin{tabular}{|c|c|c|c|}
\hline Cost Category & Base Case & $\begin{array}{c}\text { Intra-region } \\
\text { Expansion } \\
\text { (percent difference } \\
\text { from Base Case) }\end{array}$ & $\begin{array}{c}\text { Copperplate } \\
\text { (percent difference } \\
\text { from Base Case) }\end{array}$ \\
\hline Fuel & 378,181 & $\begin{array}{c}369,673 \\
(-2.2 \%)\end{array}$ & $\begin{array}{l}368,777 \\
(-2.5 \%)\end{array}$ \\
\hline $\begin{array}{l}\text { Start \& } \\
\text { Shutdown }\end{array}$ & 6,233 & $\begin{array}{c}6,47 \\
(3.8 \%)\end{array}$ & $\begin{array}{l}6,505 \\
(4.4 \%)\end{array}$ \\
\hline $\begin{array}{l}\text { Variable } \\
\text { Operations \& } \\
\text { Maintenance }\end{array}$ & 20,743 & $\begin{array}{l}20,734 \\
(0.0 \%)\end{array}$ & $\begin{array}{l}20,732 \\
(0.1 \%)\end{array}$ \\
\hline Total & 405,158 & $\begin{array}{c}396,880 \\
(2.0 \%)\end{array}$ & $\begin{array}{c}396,773 \\
(2.3 \%)\end{array}$ \\
\hline
\end{tabular}

Additional region-wise transmission expansion, as represented in the Copperplate scenario, has marginal additional production cost benefits compared to Intra-region Expansion. However, the Copperplate scenario has the largest effect on daily transmission flow patterns. Figure 15 depicts average hourly flows across regional interfaces in each transmission expansion scenario. Expanded transmission capacity results in increased power flow to the Northern region. Compared to the Base Case, the annual net import in the Northern region increases by $15 \%$ or 27.8 TWh in the Copperplate scenario. Average hourly flows from the Western region to the Northern region increase across all periods of the day, especially in the middle of the day when solar generation is highest. This trend points to the increasing role of power wheeling to the Northern region from high-RE states in the Eastern and the Southern regions. The increased flow through the Western region reduces power wheeling via the NER-NR DC interconnection tie. The Northeastern region continues to export hydro generation during morning and evening hours when solar resources are not available.

\footnotetext{
${ }^{16}$ All potential cycling costs to thermal plants are not captured in the model, only the additional cost of starting up and shutting down plants. Other cycling costs include maintenance costs from wear and tear of plant components having to turn up and down more often from a more variable net load. Other studies have concluded that these costs are likely small (Lew et al. 2013), and their inclusion is beyond the scope of this study. USAID's GTG project has ongoing work that looks closely at coal cycling for the India power system (USAID 2019).
} 

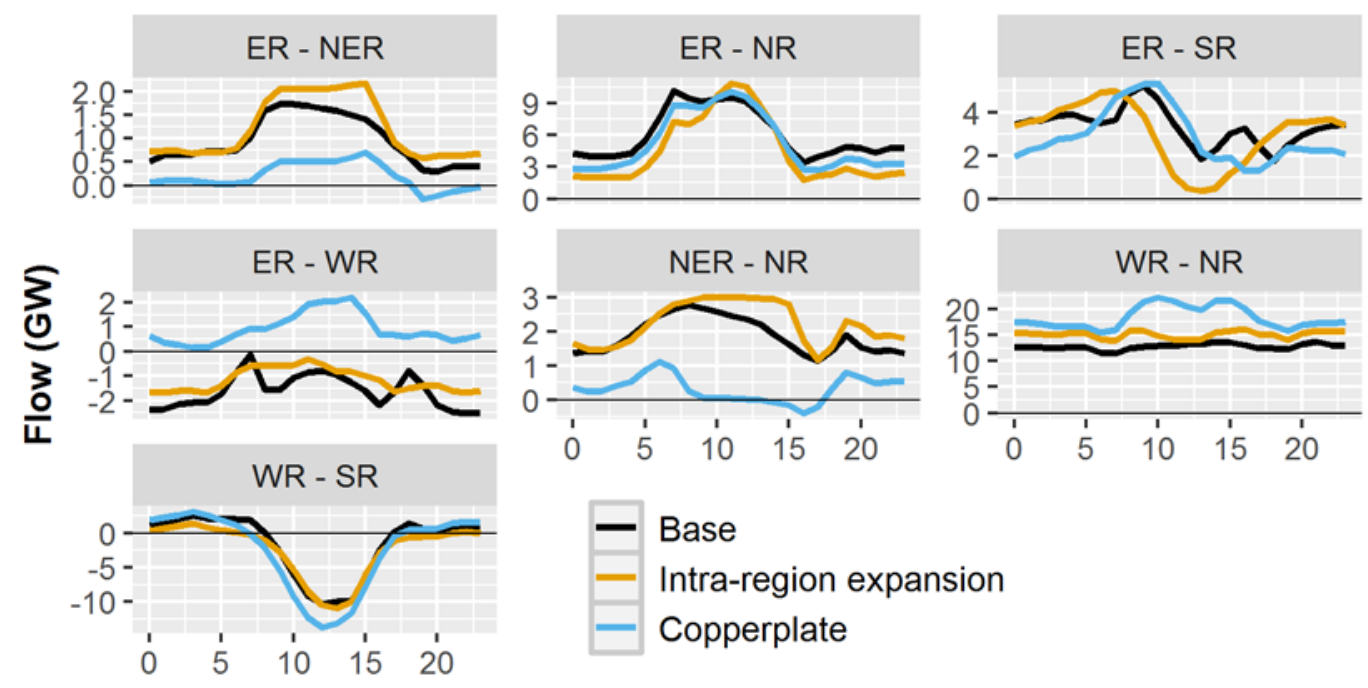

Base
Intra-region expansion
Copperplate

Hour

Figure 15. Average daily interface flow across regional transmission interfaces

Negative values represent flow in opposite direction to interface name (e.g., WR - SR with negative flow means that power is flowing from $S R$ to WR). ER=Eastern region, NER=Northeastern region, NR=Northern region, $S R=S o u t h e r n$ region, WR=Western region

Increased power flow to the Northern region occurs because of the generation cost disparities between regions, which we examine through the relative short-run marginal cost (SRMC) of generation in India's regions. ${ }^{17}$ Figure 16 depicts the median hourly SRMC by month in each region. The Northern region has the highest median SRMC during daytime hours, particularly during in December, January, July and August. Lower-cost generation from other regions is wheeled to the Northern region during these hours. The Northeastern region has the lowest average daytime SRMC due to availability of low-cost hydro generation. The Southern region SRMC is highest in the early morning and evening hours when solar generation is not available. The Copperplate scenario shows increased power flow from Eastern region to Southern region during these hours (top-right panel of Figure 15).

\footnotetext{
${ }^{17}$ SRMC is the cost of generating the next unit of energy in the region and is often representative of the most expensive online generator (marginal generator). We are using this as a proxy for locational marginal pricing (LMP) to avoid complicated introductions of transmission congestion and other inputs to LMP calculations, while still allowing for an analysis of energy generation price differences across regions.
} 


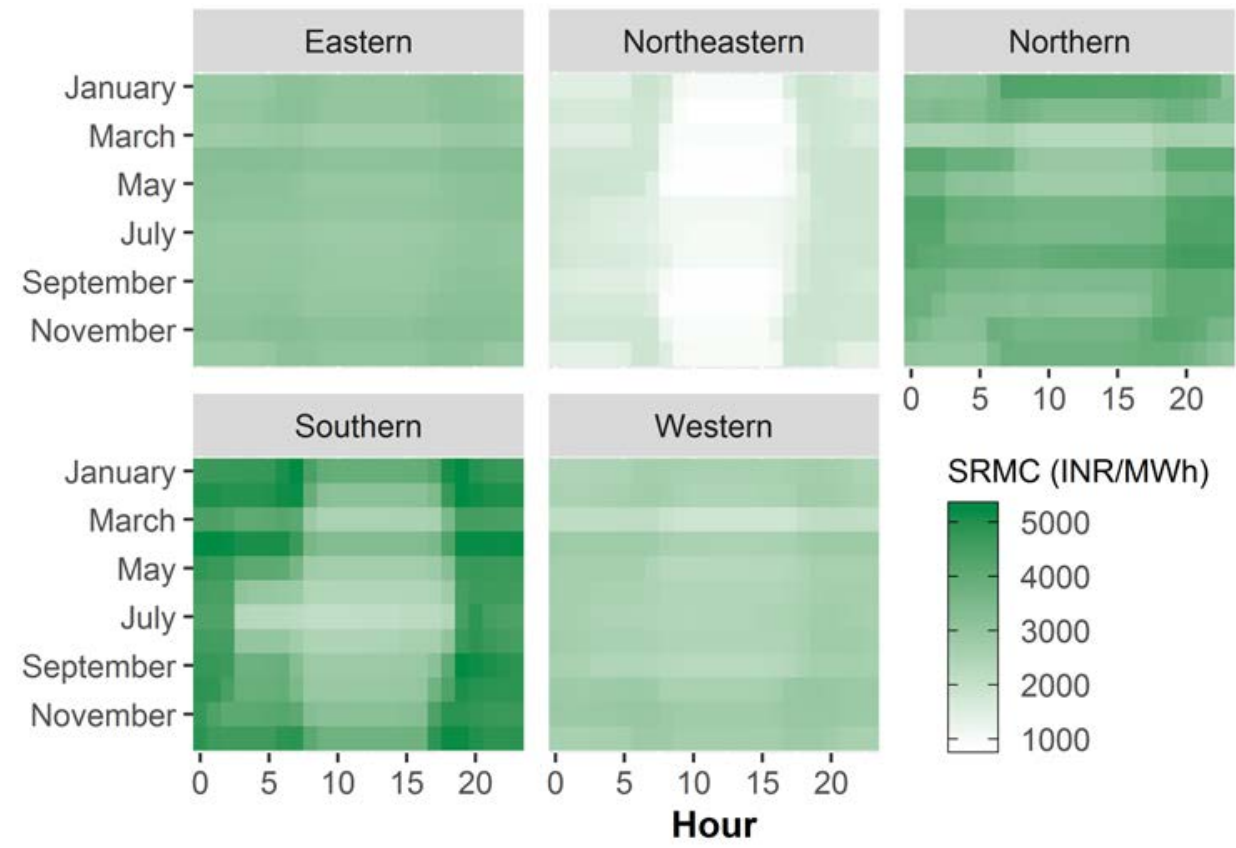

Figure 16. Short run marginal cost of generation in India regions

Color indicates average value

\subsection{Supply and Demand Balance}

In all transmission scenarios we found that some periods of the year had unserved energy demand, resulting from an imbalance of demand and supply. Unserved energy can happen for several reasons in our model, including low available generation capacity, transmission constraints, low fuel availability, or the inability of online generators to ramp fast enough to meet fluctuations in load. ${ }^{18,19}$ Analyzing the copperplate scenario allows us to exclude transmission constraints causing unserved energy. However, even in this scenario we still found annual unserved energy of $339 \mathrm{GWh}$, or $0.01 \%$ of total demand. Unserved energy events, while infrequent, can be substantial, reaching over $4 \%$ of demand in certain hours of the year ${ }^{20}$. This section examines the circumstances that lead to unserved energy through an analysis of one the most challenging weeks to serve load.

The result of unserved energy, or dropped load, in the model agrees with the analysis of a similar scenario by TERI (Spencer and Awasthy 2019) and separately CPI (Udetanshu et al. 2019), which also uses the TERI demand projections. Most of the unserved energy in our model takes

\footnotetext{
${ }^{18}$ Hydro plants are the only generators with fuel (i.e., water) availability constraints in the model. Gas plants also have fuel limitations; however, as explained in Section 2.2.2.2, this is modeled as generator outages so that availability is scheduled for the year as opposed to optimized for generation in real time when needed.

${ }^{19}$ Our analysis only considers normal operating conditions and not contingency events. A robust framework for analyzing loss-of-load events would include using probabilistic methods, such as loss of load probability, to measure the potential of dropped load. However, this is outside the scope of this analysis.

${ }^{20}$ The provision of operating reserves is modeled such that the model will always choose to serve energy before holding reserves. Therefore, any periods with unserved energy also have no provisioned reserves. Annually, operating reserves were able to be provisioned for $97 \%$ of the energy requirement.
} 
place in September and October when the demand is peaking and other resources, such as wind and hydro have lower availability.

One of the most challenging weeks for balancing supply and demand is at the end of September when India reaches its peak load on September $25^{\text {th }}$ at 19:00, and has several other relatively high load days around the 25th. Figure 17 shows the generation dispatch for the week of September $25^{\text {th }}$. The unserved energy during this week amounts to almost $40 \%$ of the total for the year, which takes place in the periods of daily national peaks, between the hours of 19:00 and 22:00. During the peak hours most of the load is met by dispatchable resources of thermal, hydro, and gas, while wind is providing an average of $5.5 \%$ of the generation. Solar has recently ramped down for the day.

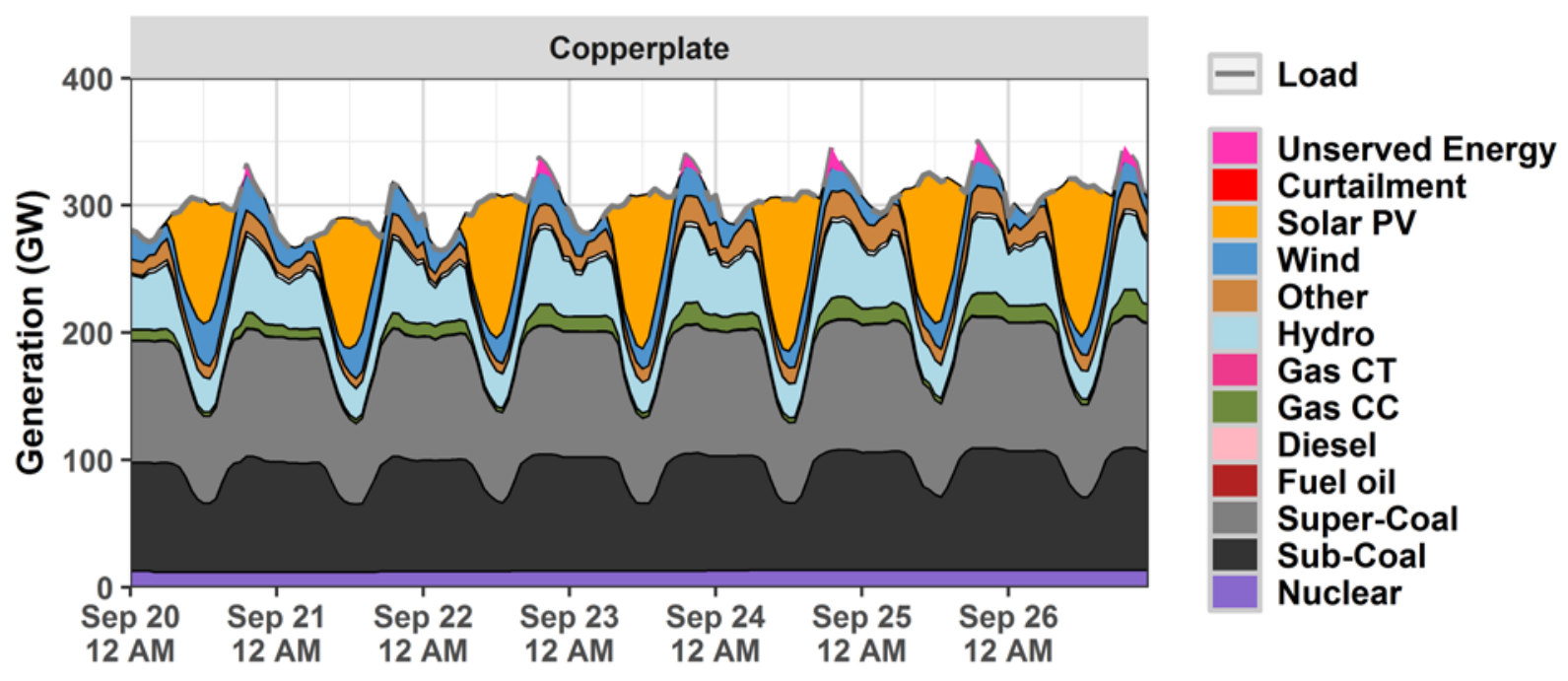

Figure 17. Generation dispatch in the Copperplate scenario during peak India load

During the week of September $25^{\text {th }}$ dispatchable resources are operating at their maximum capacity to help serve peak load, as indicated in Figure 18, which shows the available capacity and generation for thermal, hydro-storage, and gas for the same September week. Each category of plants is turning down during the day when solar availability is high and ramping up to its maximum amount during the peak load times when solar is not available. 


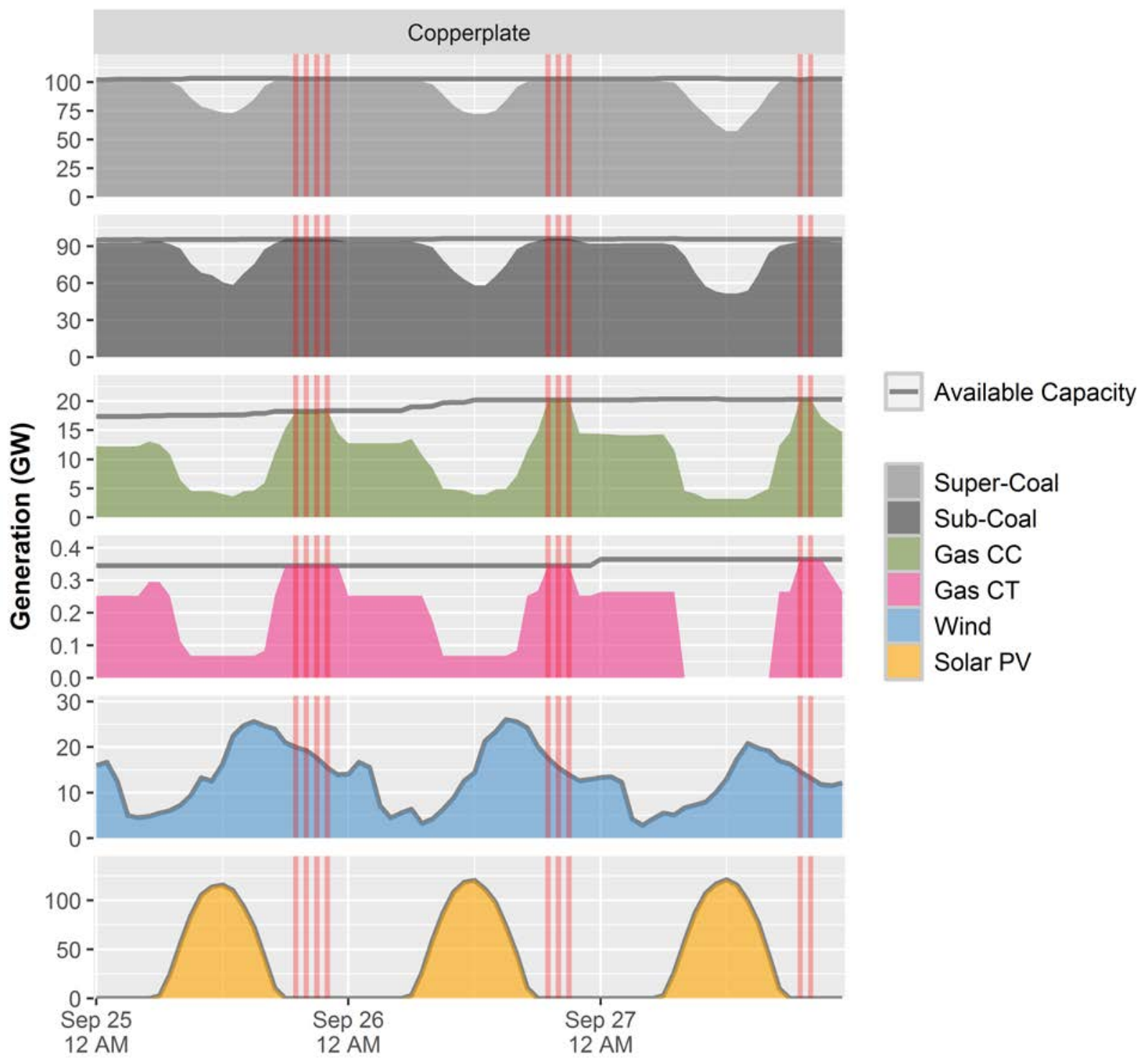

Figure 18. Hourly committed capacity and generation dispatch for three days in September, Copperplate scenario

Red bars indicate hours with USE 
The ability of the generators to reach full output during peak periods, combined with the total installed capacity, indicates that there should be an adequate supply of generation. ${ }^{21}$ However, unserved energy occurs because available capacity is not present due to thermal and gas generators being turned off for outage. ${ }^{22}$

As described in section 2.2.2.2, generator outages occur for two reasons in our model: maintenance (planned) outages and forced (unplanned) outages. Maintenance outages are distributed throughout the year to maximize capacity reserves, resulting in a somewhat optimal distribution of maintenance events that avoid outages during peak load times. Forced outages are randomly distributed throughout the year. However, the state-centric structure of our model is also considered in the scheduling of outages, which convolutes the planning for peak load periods. Each state seeks to reduce the outages of its fleet during the individual state peak demand. Figure 19 shows the distribution of peak loads for India and all the individual states. Many of the largest demand states have peaks shortly after India's coincident peak.

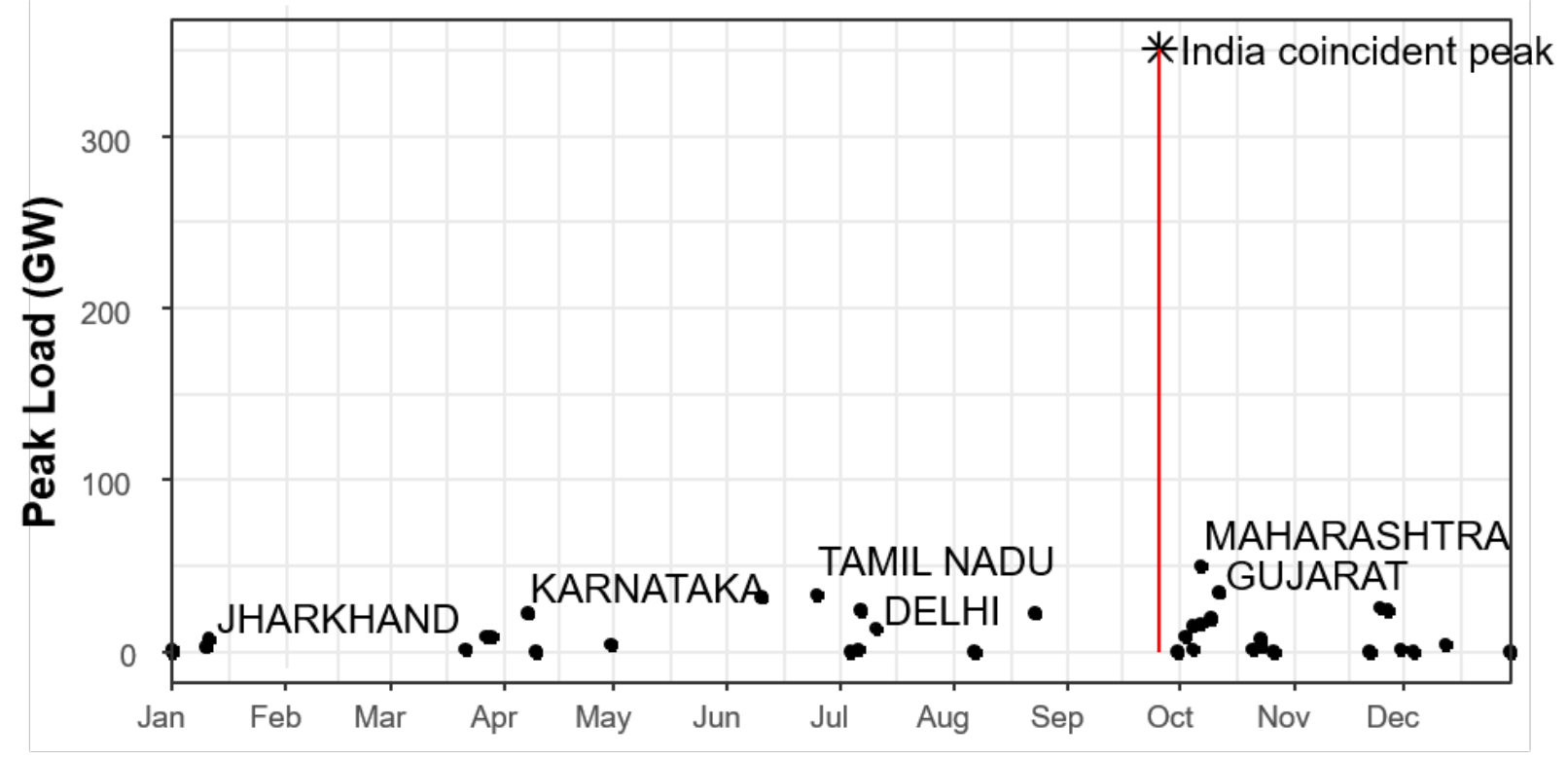

Figure 19. Distribution of peak loads by state and for all of India

The non-coincident timing of India's peak load, and the likely correlated, but ultimately unfortunate timing happening just weeks before many large demand states, leads to many of the larger load states scheduling maintenance during the national peak in preparation for their own peak in the weeks ahead. Figure 20 shows the total outages for the coal fleet for India and

\footnotetext{
${ }^{21}$ Seasonal planning reserve margins (PRM) in major wholesale electricity markets in the United States are typically between 10 and $20 \%$ depending on demand growth (NERC 2016)). The approach to calculating PRM varies widely between jurisdictions. As a simplistic version of PRM in the 2030 India model, installed capacity of non-renewables for the 2030 model (Table 1, plus $22 \mathrm{GW}$ of biomass and $4.4 \mathrm{GW}$ designated imports from Bhutan) gives a PRM over $8 \%$. Including the $20 \mathrm{GW}$ of wind available during peak load gives a PRM of close to $15 \%$.

${ }^{22}$ Low capacity causing unserved energy was confirmed by a series of test simulations or that reduced or eliminated outage rates. Reducing gas outages to zero led to roughly halving unserved energy, and eliminating all outages on coal and gas led to no unserved energy. Generator ramping, another potential constraint that would cause unserved energy, was also not hitting limits in any periods.
} 
Maharashtra for the year. The lowest capacity of maintenance outages is shortly after the India peak load in late September, aligning with the cluster of state peak loads in early October. This sequence of optimal planning at the state-level leads to the unserved energy in late September. The last week of September has four of the ten highest load periods in the year, yet the scheduled outage capacity during peak load is about average, at $38 \mathrm{GW}$. Similar sequences of poor coordination in outage planning lead to additional unserved energy in other coincident peak load times.

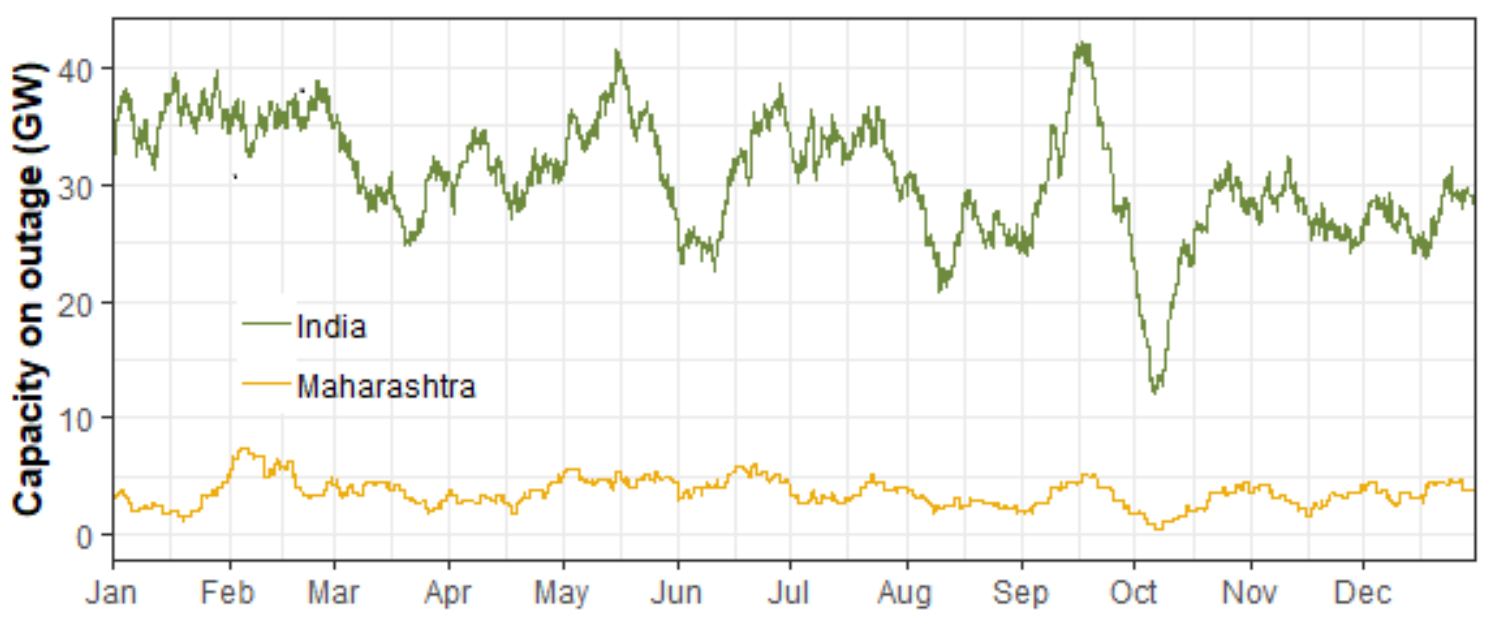

Figure 20. Total coal fleet outages for India and Maharashtra

While the planning of outages demonstrated in the model may not align exactly with the practices in India now or in the future, it does highlight a planning consideration that will become more relevant as India's thermal fleet reaches higher capacity factors and RE becomes a larger percentage of installed capacity: that coordination will lead to increased reliability. Better coordination in the short-term planning stages will also enable more optimal use of the transmission network. While the model considered the ability of states to import and export through their interconnections to other states while planning the outages, the available capacity in those states is not considered. This lack of visibility into other state plans led to the India-wide low capacity during peak demand. 


\section{Conclusion}

The base scenario analyzed in this interim report demonstrates that a $22 \%$ annual penetration of wind and solar is manageable by India's grid. Most days in the year do not show signs of stress, and $99.97 \%$ of energy is served with the plans as presented. However, the results highlight specific challenges the grid may face during a small number of high-demand periods. Additionally, the PLFs of coal plants, which are causing concern by hovering around $60 \%$ in today's system (Patel 2018), have risen to 70\% in the Base Case, giving better signals for revenue sufficiency. With curtailment of RE at $2.3 \%$ without any major changes to current or planned system operations, the trajectory of system plans is, from an operations perspective, not substantially different from what might be expected in 2022 (Palchak et al. 2017).

This study also offers insights into the possible outcome of increased transmission capacity. Operational cost savings and increased system efficiency are the principal outcomes of increasing interstate and inter-region connection capacity. Most of the cost benefit and reduction in RE curtailment of increased transmission is realized when the intra-region transmission system is expanded, however expanding region-to-region connections also produces benefits. The most notable change of inter-region expansion is the increased power wheeling through the Western region, with more power flowing to the Northern region from high-RE states in Eastern and Southern regions. Future work will expand on the transmission scenarios to understand what corridors might be economically viable for expansion, rather than the whole system expansion explored in this report.

While most energy can be served given the model parameters, the periods of stress are useful for thinking about reliability in the future. Unserved energy under normal operating conditions runs counter to the standard principles of designing an electricity system to be able to meet peak load, and attention to these periods is valid. The identification of outage scheduling as a culprit in causing unserved energy is less about low capacity, and more about low coordination among states. Future work will explore reliability through state-of-the-art industry metrics and planning tools and seek to understand how RE will contribute to reliability in the future.

Lastly, a primary objective of the interim report is to establish a baseline scenario roughly in line with India's electricity system planners for exploring questions about India's 2030 electricity system. Doing so required cross-referencing multiple sources of data about each generator on the system and all planned capacity of both transmission and generation. Future work involves building a broader set of analysis with different scenarios for capacity of both generation and transmission. Specifically, using cost-optimal planning tools and methods to expand the electricity system, including the consideration of transformative technologies such as storage or demand response. Changes to demand, as outlined in TERI's report will also be considered (Spencer and Awasthy 2019). 


\section{References}

CEA. 2017. "Nineteenth Electric Power Survey of India - Volume I." Central Electricity Authority.

CEA. 2018. "National Electricity Plan - Volume I: Generation." New Delhi: Central Electricity Authority. http://www.cea.nic.in/reports/committee/nep/nep_jan_2018.pdf.

CEA. 2019. "Flexible Operation of Thermal Power Plant for Integration of Renewable Generation." New Delhi: Central Electricity Authority. http://www.cea.nic.in/reports/others/thermal/trm/flexible_operation.pdf.

CERC. 2018a. "Detailed Procedure for 'Grant of Connectivity to Projects Based on Renewable Sources to Inter-State Transmission System."” Annexure. New Delhi: Central Electricity Regulatory Commission (CERC). https://webapps.powergrid.in/ctu/docs/files/regulations detailed procedures/Approved\%20Detai led\%20Procedure $\% 20$ for $\% 20$ Renewable $\% 20$ Energy $\% 20$ Sources.pdf.

CERC. 2018b. "Discussion Paper on 'Re-Designing Real Time Electricity Market in India."” Central Electricity Regulatory Commission (CERC). http://www.cercind.gov.in/2018/draft reg/25.pdf.

CERC. 2019. Pilot on Security Constrained Economic Dispatch (SCED) of Inter-State Generating Stations (ISGS) Pan India. Petition No. 02/SM/2019. https://posoco.in/wpcontent/uploads/2019/03/SCED_CERC_Signed_Order_134-2009.pdf.

GOI. 2015. "India's Intended Nationally Determined Contribution: Working Towards Climate Justice.” INDC. New Delhi: Government of India. https://www4.unfccc.int/sites/ndcstaging/PublishedDocuments/India\%20First/INDIA\%20INDC \%20TO\%20UNFCCC.pdf.

Joint Technical Team (JTT) of India and Bangladesh. 2016. "Report on the Feasibility of Additional Interconnection between India and Bangladesh." New Delhi: CEA. http://www.cea.nic.in/reports/committee/scm/ner/agenda note/annex3.pdf.

Lew, D., G. Brinkman, Eduardo Ibanez, Anthony Florita, Bri-Mathias Hodge, M. Heaney, M. Hummon, et al. 2013. "The Western Wind and Solar Integration Study Phase 2." Technical Report NREL/TP-5500-55588. Golden, CO: National Renewable Energy Laboratory. https://www.nrel.gov/docs/fy13osti/55588.pdf.

McBennett, Brendan, Amy Rose, David Hurlbut, David Palchak, and Jaquelin Cochran. 2019. "Cross-Border Energy Trade between Nepal and India: Assessment of Trading Opportunities." Technical Report NREL/TP-6A20-72066. Golden, CO: National Renewable Energy Laboratory. https://www.nrel.gov/docs/fy19osti/72066.pdf.

MNRE. 2018. "Year End Review 2018." Press Release. Ministry of New and Renewable Energy. December 10, 2018. http://pib.nic.in/newsite/PrintRelease.aspx?relid=186228. 
MNRE. 2019. "Compendium of Regulations and Policies on Renewable Energy." Ministry of New and Renewable Energy. 2019. https://mnre.gov.in/compendium-regulations-and-policiesrenewable-energy-2019.

NERC. 2016. "2016 Long-Term Reliability Assessment." Atlanta, GA: North American Electric Reliability Corporation (NERC). https://www.nerc.com/pa/RAPA/ra/Reliability\%20Assessments\%20DL/2016\%20LongTerm\%20Reliability\%20Assessment.pdf.

Pachouri, Raghav, Thomas Spencer, and G. Renjith. 2019. "Exploring Electricity Supply-Mix Scenarios to 2030." New Delhi: The Energy and Resources Institute (TERI). https://www.teriin.org/sites/default/files/2019-02/Exploring\%20Electricity\%20SupplyMix\%20Scenarios\%20to\%202030.pdf.

Palchak, David, Jaquelin Cochran, Ali Ehlen, Brendan McBennett, Michael Milligan, Ilya Chernyakhovskiy, Ranjit Deshmukh, et al. 2017. "Greening the Grid: Pathways to Integrate 175 Gigawatts of Renewable Energy into India's Electric Grid, Vol. I—National Study.” National Renewable energy Laboratory, USAID and Ministry of Power. https://www.nrel.gov/docs/fy17osti/68530.pdf.

Patel, Sonal. 2018. "India's Coal Glut Leaves Producers Teetering on Bankruptcy." POWER Magazine. October 1, 2018. https://www.powermag.com/indias-coal-glut-leaves-producersteetering-on-bankruptcy/.

Power Grid Corporation of India. 2012. "Transmission Plan for Envisaged Renewable Capacity." https://www.powergridindia.com/sites/default/files/Our_Business/Smart_Grid/Green_Energy_C orridor_Report/Vol_1.pdf.

Power Grid Corporation of India. 2019. “TTC-ATC for May 2019.” Power Grid Corporation of India. https://webapps.powergrid.in/ctu/docs/files/TTC\%20ATC/TTC\%20ATC\%20201516\%20\%26\%202016-17/TTC-ATC\%20for\%20May'19-R0(1).pdf.

Shah, Kashish, and Tim Buckley. 2019. "IEEFA India: Continued Decline in Indian Thermal Capacity Additions." Institute for Energy Economics \& Financial Analysis (blog). April 10, 2019. http://ieefa.org/ieefa-india-continued-decline-in-indian-thermal-capacity-additions/.

Spencer, Thomas, and Aayushi Awasthy. 2019. "Analysing and Projecting Indian Electricity Demand to 2030.” New Delhi: The Energy and Resources Institute (TERI). https://www.teriin.org/sites/default/files/201902/Analysing\%20and\%20Projecting\%20Indian\%20Electricity\%20Demand $\% 20$ to\%202030.pdf.

Udetanshu, Brendan Pierpont, Saarthak Khurana, and David Nelson. 2019. "Developing a Roadmap to a Flexible, Low-Carbon Indian Electricity System: Interim Findings." London: Climate Policy Initiative. https://climatepolicyinitiative.org/wp-content/uploads/2019/02/CPIIndia-Flexibility-February-2019.pdf.

USAID. 2019. "Flexible Power Generation." Greening the Grid (GTG) Renewable Integration and Sustainable Energy Initiative (blog). 2019. https://www.gtg-india.com/flexible-power-generation/. 